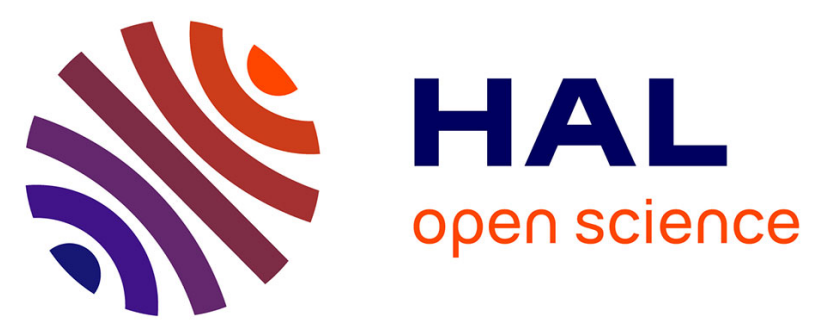

\title{
Modeling and optimization of a photocatalytic process: Degradation of endocrine disruptor compounds by $\mathrm{Ag} / \mathrm{ZnO}$
}

Alma Berenice Jasso-Salcedo, Sandrine Hoppe, Fernand Pla, Vladimir Alonso Escobar-Barrios, Mauricio Camargo, Dimitrios Meimaroglou

\section{To cite this version:}

Alma Berenice Jasso-Salcedo, Sandrine Hoppe, Fernand Pla, Vladimir Alonso Escobar-Barrios, Mauricio Camargo, et al.. Modeling and optimization of a photocatalytic process: Degradation of endocrine disruptor compounds by $\mathrm{Ag} / \mathrm{ZnO}$. Chemical Engineering Research and Design, 2017, 128, pp.174 191. 10.1016/j.cherd.2017.10.012 . hal-01629305

\section{HAL Id: hal-01629305 \\ https://hal.univ-lorraine.fr/hal-01629305}

Submitted on 8 Feb 2018

HAL is a multi-disciplinary open access archive for the deposit and dissemination of scientific research documents, whether they are published or not. The documents may come from teaching and research institutions in France or abroad, or from public or private research centers.
L'archive ouverte pluridisciplinaire HAL, est destinée au dépôt et à la diffusion de documents scientifiques de niveau recherche, publiés ou non, émanant des établissements d'enseignement et de recherche français ou étrangers, des laboratoires publics ou privés. 
4 Alma Berenice Jasso-Salcedo ${ }^{\mathrm{a} 1}$, Sandrine Hoppe ${ }^{\mathrm{b}}$, Fernand $\mathrm{Pla}^{\mathrm{b}}$, Vladimir Alonso Escobar-Barrios ${ }^{\mathrm{c}}$,

5 Mauricio Camargo ${ }^{d}$ and Dimitrios Meimaroglou ${ }^{b^{*}}$

6 a Instituto Potosino de Investigación Científica y Tecnológica, División Ciencias Ambientales, Camino a la Presa de

7 San José 2055, Col. Lomas 4a Sección. C.P. 78216, San Luis Potosí, S.L.P., México.

$8 \quad{ }^{b}$ CNRS, Laboratoire Réactions et Génie des Procédés, Université de Lorraine UMR 7274, Nancy, F-54001, France.

9 CInstituto Potosino de Investigación Científica y Tecnológica, División de Materiales Avanzados, Camino a la Presa

10 de San José 2055, Col. Lomas 4a Sección. C.P. 78216, San Luis Potosí, S.L.P., México.

11 dUniversité de Lorraine, ERPI, Equipe de Recherche sur les Processus Innovatifs, EA 6737, Nancy, F-54001, France.

12

efficiency in terms of the degradation reaction rate. Two ANN models were developed to 24 simulate the stages of the photocatalyst synthesis and photodegradation performance,

*Corresponding author e-mail address: dimitrios.meimaroglou@univ-lorraine.fr

${ }^{1}$ Present address author AB Jasso-Salcedo: Department of Materials and Environmental Chemistry, Arrhenius Laboratory, Stockholm University, SE-106 91 Stockholm, Sweden.

Keywords: artificial neural networks, optimization, photocatalysis, bisphenol-A.

\section{Abstract}

Artificial neural network (ANN) modeling was applied to study the photocatalytic degradation of bisphenol-A. The operating conditions of the $\mathrm{Ag} / \mathrm{ZnO}$ photocatalyst synthesis and its performance were simultaneously modeled and subsequently optimized to target the highest 
25 respectively. A direct dependence between the two networks was also established, thus making

26 it possible to directly relate the degradation rate of the contaminant, not only to the

27 photodegradation conditions, but also to the photocatalyst synthesis conditions. In this respect,

28 an optimization study was carried out, by means of an evolutionary algorithm, in order to

29 identify the optimal synthesis and photodegradation conditions that would result in the

30 degradation of a maximal amount of the contaminant. Through this integrated approach it was

31 demonstrated that neural network models can be proven valuable tools in the evaluation,

32 simulation and, ultimately, the optimization of different stages of complex photocatalytic

33 processes towards the maximization of the efficiency of the synthesized photocatalyst.

34 


\section{Introduction}

Endocrine-disrupting compounds (EDCs) is a class of chemical substances that pollute water and other environmental resources. They are responsible for adverse developmental, reproductive, neurological and immune side-effects on both humans and wildlife as they interfere with the organism's endocrine system. Bisphenol-A (BPA) is an EDC that was used initially (i.e., in the 1930's) as an estrogenic drug for birth control and later as a monomer in the synthesis of polycarbonate as well as an additive in the synthesis of polyvinylchloride, polyesters, epoxy resins, lacquer coatings, etc. It is these latter applications that have facilitated the extensive, worldwide spread of this contaminant, presently detected in various aqueous media including fresh and marine surface waters and groundwater (Flint et al., 2012; Klečka et al., 2009).

Among the several studies on the removal of EDCs and pharmaceuticals from drinking water, sunlight-induced photocatalytic degradation is an attractive approach that has gained significant attention over the last years (Bohdziewicz et al., 2016; Esplugas et al., 2007; Fernández et al., 2014; Sin et al., 2012; Sornalingam et al., 2016; Tijani et al., 2013). Yet, despite the undisputed advantages of the process, such as its clean - non-chemical nature and its relatively low cost, heterogeneous photocatalysis is a complex process whose efficiency is related to a number of factors associated with the catalyst properties (e.g., crystal structure, morphology, surface area, defect sites, polarity, active surface sites and reactive charges lifetime) and the photocatalytic reaction conditions (e.g., pH, contaminant concentration, catalyst dose, light intensity). Hence, the control of the photocatalytic performance of UV/Metal Oxide systems is not a trivial problem since it requires an optimal combination of the above 
57 mentioned material and process characteristics and conditions. In this respect, the

58 development of an accurate robust mathematical model of the process becomes of profound

59 importance to the study and implementation of this decontamination technique.

60 Traditional modeling approaches of such systems are based on kinetic models that simulate the

61 contaminant degradation curves on the basis of a commonly adopted first-order kinetics

62 equation (Amani-Ghadim \& Seyed Dorraji, 2015; Rosenfeldt \& Linden, 2004; R. Wang et al.,

63 2009). On the other hand, alternative modeling methodologies (e.g., empirical models or

64 response surface methodologies) (Asl et al., 2012; Babaei et al., 2011; Kiattisaksiri et al., 2015;

65 Lee \& Hamid, 2015; Merabet et al., 2016) are constantly gaining ground in the area, mainly due

66 to the complex nature of the photodegradation processes and the lack of thorough

67 understanding of all the mechanisms involved, which inhibits the development of generalized

68 powerful mechanistic models. Among these alternatives, Artificial Neural Network models

69 display an evergrowing presence in the most recent relevant studies.

70 Artificial Neural Networks (ANN) are powerful tools that can be implemented on a set of raw

71 experimental data to establish non-linear mathematical relations between the input/output of

72 the process. They belong to the general class of 'data-driven models' (DDM), which attempt to

73 create connections between the input variables and the responses of a system, without

74 requiring any prior knowledge on the underlying physical phenomena (Solomatine et al., 2008).

75 Other advantages of this class of models are their ability to extract and recognize patterns in

76 data, as well as their rather quick and simple development and implementation to completely

77 different processes. 
Under the condition of existence of a sufficient number of experimental data, ANN models can

be proven quite efficient and accurate, both in correlating the existing data as well as in predicting the system behavior (within the limits of the explored experimental space), while they can also be easily customized to different systems. They are commonly developed with the aid of specifically designed software or software package toolboxes (e.g., the ANN toolbox of Matlab $\left.{ }^{\circledR}\right)$, which are simple to use and quite flexible in terms of the customization of the model structure and characteristics (Sivanandam et al., 2006).

A review of the implementation of ANN on heterogeneous photocatalytic water and wastewater treatment processes was published by Khataee and Kasiri (2010). The accuracy of ANN models was also assessed in a recent study by Amani-Ghadim and Seyed Dorraji (2015), who compared three different model types, namely a kinetic model, an empirical model and an ANN model on the photodegradation of Acid blue 9 using UV/ZnO. In this study, the authors investigated the effect of different factors (i.e., contaminant initial concentration, $\mathrm{ZnO}$ content, light intensity, $\mathrm{pH}$ and time) on the photodegradation efficiency and concluded that ANN modeling allows an accurate description of the photocatalytic process without the necessity to resort to complex mathematical descriptions of the kinetics.

Traditionally, ANN models have been applied to photocatalytic degradation processes in order to study the effect of a variety of reaction conditions on the photocatalytic performance by means of percentage of degradation or removal efficiency. It is only recently that the apparent reaction rate constant of a first-order photocatalytic degradation curve was considered as the simulated response of the developed ANN model (Behnajady \& Eskandarloo, 2015; Delnavaz, 2015). The characteristics of a series of similar recent studies are summarized in Table 1. 
100

101

102

103

104

105

106

107

108

109

110

111

112

113

114

115

116

117

118

119

120

As can be seen, ANN models can be used to assess the effect of numerous important factors of the process, such as light intensity, organic/inorganic ions concentration and oxygen dose, which influence the photocatalytic performance but are rarely considered in kinetic models. For instance, Vaez et al. (2015) studied the effect of anions naturally present in wastewater (i.e., sulfate $\mathrm{SO}_{4}{ }^{2-}$, chloride $\mathrm{Cl}^{-}$, bicarbonate $\mathrm{HCO}_{3}{ }^{-}$and carbonate $\mathrm{CO}_{3}{ }^{2-}$ ) and peroxide, on the photodegradation of Acid Red 73 on $\mathrm{UV} / \mathrm{TiO}_{2}$ nanoparticles immobilized on sackcloth fiber. In another noteworthy example, Tanasa et al. (2013) successfully studied the effect of both photocatalyst properties (i.e., crystallite size, surface area and absorption edge) and reaction conditions (i.e., dye initial concentration, time and catalyst dose) on the color removal of Eosin $\mathrm{Y}$ in UV/ZnO/SnO $\mathrm{S}_{2}$ systems.

In the present work, a novel modeling framework is proposed for the study of a photocatalytic degradation process of a water contaminant. In this respect, the two major stages of the photocatalytic process, namely the photocatalyst synthesis and the contaminant degradation experiments, are decoupled in order to separately assess the effects of the factors affecting these two process stages on the overall photocatalytic efficiency of the synthesized photocatalyst. Two artificial neural networks are developed for the modeling of these two stages, linked together by the fact that the output of the ANN model on the photocatalyst synthesis is, at the same time, an input for the ANN model on the photodegradation experiments. In a subsequent optimization analysis, the two models are separately optimized in the inverse order (i.e., starting from the model on the photodegradation tests), thus connecting the photodegradation efficiency (i.e., related to the objective function of the first optimization 
121 study on the second ANN model) with the photocatalyst synthesis conditions (i.e., optimal 122 decision variables of the second optimization study on the first ANN model).

123 The system under study concerns the use of silver-modified $\mathrm{ZnO}$ particles $(\mathrm{Ag} / \mathrm{ZnO})$ as effective 124 catalysts for the photodegradation of BPA in water. $\mathrm{ZnO}$, charged with silver nanoparticles 125 (AgNPs), is a prominent photocatalyst that has been employed in several contaminant 126 photodegradation studies due to its decreased charge-carriers recombination rate, increased 127 photostability and efficiency (Georgekutty et al., 2008; J. Wang et al., 2011; Xie et al., 2010). 128 The detailed characteristics of the experimental system have been extensively presented in a 129 recent publication (Jasso-Salcedo et al., 2016) and will not be the subject of the present work. 130 To the best of the authors' knowledge, this is the first time that a two-stage, de-coupled ANN 131 modelling framework is proposed for the study and, subsequently, the optimization of the 132 photocatalytic degradation of an endocrine disrupting contaminant. The proposed approach 133 allows for the evaluation of the effects of the factors of the two principal stages of the 134 photodegradation process (i.e., the catalyst synthesis and the degradation experiments) on the 135 final photodegradation efficiency, by distinguishing these two stages without completely 136 isolating them from the overall process. 
139 Table 1. Neural Network modeling studies of the photocatalytic performance on the degradation of water contaminants.

\begin{tabular}{|c|c|c|c|c|c|c|}
\hline Photocatalyst & Model contaminant & $\begin{array}{l}\text { ANN Topology } \\
\text { (In:Hid:Out) }\end{array}$ & $\begin{array}{c}\text { Data } \\
\text { number }\end{array}$ & Input / Factors & Output / Response & Reference \\
\hline $\mathrm{ZnO}$ & Acid Blue 9 & 5:9:1 & 152 & $\mathrm{AB9}, \mathrm{pH}, \mathrm{ZnO}, \mathrm{UV}$ intensity & Degradation efficiency (\%) & $\begin{array}{l}\text { Amani-Ghadim and } \\
\text { Seyed Dorraji (2015) }\end{array}$ \\
\hline ZnO/Montmorillonite $\mathrm{K} 10$ & $\begin{array}{l}\text { Disperse Red } 54 \\
\text { (DR54) }\end{array}$ & $5: 10: 1$ & N/A & DR54, ZnO/MMT, time & Decolorization efficiency (\%) & Kiransan et al. (2015) \\
\hline & & & & $\mathrm{BY} 28, \mathrm{ZnO} / \mathrm{MMT}$ dosage, UV radiation & & \\
\hline ZnO/Montmorillonite $\mathrm{K} 10$ & Basic yellow 28 (BY28) & $3: 14: 1$ & N/A & time & Decolorization efficiency (\%) & $\begin{array}{l}\text { Kıransan et al. (2015) } \\
\text { Behnajady and }\end{array}$ \\
\hline $\mathrm{TiO}_{2}$ & Acid Red 27 & $4: 8: 1$ & 56 & $\mathrm{TiO}_{2}, \mathrm{AR} 27, \mathrm{pH}, \mathrm{UV}$ intensity & Reaction rate constant (Kap) & Eskandarloo (2015) \\
\hline $\begin{array}{c}\mathrm{TiO}_{2} \text {-Light expanded clay } \\
\text { aggregates }\end{array}$ & Phenol & $5: 6: 4: 2$ & 325 & $\begin{array}{c}\text { Reaction time, Phenol, } \mathrm{pH}, \mathrm{TiO}_{2}, \mathrm{UV} \\
\text { intensity } \\
\text { pH, time, anion, } \mathrm{H}_{2} \mathrm{O}_{2}, \mathrm{AR} 73\end{array}$ & $\begin{array}{l}\text { Photocatalytic reactor efficiency } \\
\text { (\%) and Kinetic constant (Kapp) }\end{array}$ & Delnavaz (2015) \\
\hline $\mathrm{TiO}_{2} /$ sackcloth fibre & Acid Red 73 & 5: $15: 1$ & 300 & $\begin{array}{c}\text { concentration } \\
\mathrm{SnO}_{2} / \mathrm{Fe}_{3} \mathrm{O}_{4} \text {, phenol red, stirring }\end{array}$ & Photocatalytic efficiency (\%) & Vaez et al. (2015) \\
\hline $\mathrm{SnO}_{2} / \mathrm{Fe}_{3} \mathrm{O}_{4}$ & Phenol red & $4: 20: 30: 20: 1$ & 30 & intensity, UV intensity & Dye removal (\%) & Sargolzaei et al 2015 \\
\hline $\mathrm{TiO}_{2} / \mathrm{ZrO}_{2}$ & Carbamazepine (CBZ) & $4: 5: 1$ & 130 & $\mathrm{TiO}_{2} / \mathrm{ZrO}_{2}, \mathrm{pH}$, reaction time, $\mathrm{CBZ}$ & $\begin{array}{c}\mathrm{CBZ} \text { removal (\%) } \\
\text { Photocatalytic reduction } \mathrm{Cr}(\mathrm{VI})\end{array}$ & $\begin{array}{l}\text { Das et al. (2014) } \\
\text { Sabonian and Behnajady }\end{array}$ \\
\hline $\mathrm{TiO}_{2}$ & Chromium (Cr (VI) & $4: 4: 1$ & 558 & $\mathrm{Cr}(\mathrm{VI}), \mathrm{pH}, \mathrm{TiO}_{2}$, irradiation time & $(\%)$ & (2014) \\
\hline $\mathrm{TiO}_{2}$ & $\begin{array}{l}\mathrm{N}, \mathrm{N} \text {-diethyl-m- } \\
\text { toluamide (DEET) }\end{array}$ & $3: 13: 1$ & 17 & $\mathrm{TiO}_{2}, \mathrm{DEET}, \mathrm{UV}$ intensity & Photocatalytic oxidation (\%) & $\begin{array}{l}\text { Antonopoulou and } \\
\text { Konstantinou (2013) }\end{array}$ \\
\hline $\mathrm{TiO}_{2}$ & $\begin{array}{l}\text { Total phenolic } \\
\text { compounds (TPh) }\end{array}$ & $3: 12: 1$ & 17 & $\begin{array}{c}\mathrm{TiO}_{2}, \mathrm{TPh}, \mathrm{UV} \text { intensity } \\
\text { Reaction time, } \mathrm{TiO}_{2}, \mathrm{EE} 2 \text {, water }\end{array}$ & $\begin{array}{c}\text { Photocatalytic } \\
\text { oxidation of TPh (\%) }\end{array}$ & $\begin{array}{l}\text { Antonopoulou et al. } \\
\text { (2012) }\end{array}$ \\
\hline $\mathrm{TiO}_{2}$ & $\begin{array}{l}\text { 17a-ethynylestradiol } \\
\text { (EE2) }\end{array}$ & $5: 13: 1$ & 222 & $\begin{array}{l}\text { dissolved organic carbon, water } \\
\text { conductivity }\end{array}$ & EE2 conversion (\%) & Frontistis et al. (2012) \\
\hline $\mathrm{TiO}_{2}$ & 4-nitrophenol (4-NP) & $4: 14: 1$ & 147 & Nano $\mathrm{TiO}_{2}$, time, UV intensity, 4-NP & Removal (\%) & Ghanbary et al. (2012) \\
\hline $\mathrm{TiO} 2$ & Reactive black 5 (RB5) & $4: 10: 1$ & N/A & $\mathrm{pH}, \mathrm{TiO}_{2}$ dose, $\mathrm{RB} 5$, time & Photocatalytic efficiency (\%) & Dutta et al. (2010) \\
\hline
\end{tabular}




\section{Methodology}

\subsection{Data collection}

\subsubsection{Preparation of $\mathrm{Ag} / \mathrm{ZnO}$}

144 The $\mathrm{Ag} / \mathrm{ZnO}$ photocatalyst was prepared by photodeposition (PD) and impregnation (IMP) 145 methods (Jasso-Salcedo et al., 2014). For both methods, a suspension containing $\mathrm{ZnO}$ and 146 stabilized silver nanoparticles (AgNPs) was adjusted at desired initial pH values using $0.1 \mathrm{~N} \mathrm{HCl}$ 147 and/or $0.5 \mathrm{~N} \mathrm{NaOH}$. The suspension was stirred under UV irradiation or in darkness, for PD and 148 IMP methods, respectively. Then the sample was submitted to centrifugation/re-dispersion 149 cycles in distilled water and ethanol solutions several times to remove the free AgNPs (i.e., not 150 attached to the $\mathrm{ZnO}$ surface). The actual weight percentage of AgNPs that were finally attached 151 to the $\mathrm{ZnO}$ surface was calculated by the following expression:

$152 \quad W_{\mathrm{Ag}} \%=\frac{W_{\mathrm{Ag}}}{W_{\mathrm{Ag}}+W_{\mathrm{Zn}}} 100$

153 where the quantities of $\mathrm{Ag}$ and $\mathrm{Zn}$ were obtained from elemental quantification using 154 inductively coupled plasma spectrometry (ICP-OES, 730-ES, Varian Inc.) at $328 \mathrm{~nm}$ and 213.9 $155 \mathrm{~nm}$, respectively. Before the analysis, the samples were submitted to acid digestion (69\% Nitric 156 acid), diluted with DI H2O and filtered (0.45 um).

\section{$157 \quad$ 2.1.2 Photocatalysis experiments}

158 An aqueous solution of BPA and photocatalyst was mechanically stirred for 10 min in darkness 159 and then irradiated at different wavelengths, namely at 254, 302 or $365 \mathrm{~nm}$ using a UV lamp 160 (3UV-38, UVP Inc.) and at $450 \mathrm{~nm}$ using a fluorescent lamp (F8T5/CW, Hampton Bay). The 
161

162 163

164 165 166 167 168 169

173 function of order $n$ :

$174 \quad r\left(=-\frac{d C_{N}}{d t}\right)=k_{a p p} C_{N}^{n}$

$C_{N}=a \exp (b t) ; b<0$ experiments were carried out in a dark box, with the lamp placed at a distance of $8 \mathrm{~cm}$ above the sample, at room temperature and without external oxygen supply (Jasso-Salcedo et al., 2014). Samples were then collected at regular time intervals and centrifuged at 3,000 rpm for $10 \mathrm{~min}$ to recover the photocatalyst powder. The liquid samples were filtered $(0.45 \mu \mathrm{m})$ before liquid chromatography (HPLC 1200 Series, Agilent Technologies) analysis.

The apparent kinetic rate constant of the BPA degradation was obtained as follows: the experimental data (i.e, BPA concentration vs time plots) were initially approximated by an exponential decay function, as shown in Eq.(2):

where $C_{N}$ denotes the normalized BPA concentration $\left(C / C_{0}\right)$. A least squares regression provided the values of $\alpha$ and $b$ for each experiment. In order to associate the BPA degradation curves with a rate constant, the differential form of Eq.(2) was then transformed into a typical rate

In the above equation, $k_{\text {app }}$ and $n$ are the apparent kinetic rate constant and the order of the 176 reaction, respectively and $r$ denotes the rate of the reaction. The values of $k_{\text {app }}$ and $n$ can be 177 estimated by substituting Eq.(2) into Eq.(3):

$178\left\{\begin{array}{c}n=1 \\ k_{a p p}=-b\end{array}\right.$

179 The first order rate of the BPA degradation was also confirmed by plotting $\ln (r) v s \ln \left(C_{N}\right)$ and 180 estimating the regression parameters of the produced straight line, according to the linearized 181 form of Eq.(3): 
$182 \ln (r)=\ln \left(k_{\text {app }}\right)+n \ln \left(C_{N}\right)$

183 Note that the value of the correlation coefficient, $R$, of this linear regression is given, for each 184 experiment, in Table 5, along with the values of the experimental measurements.

\subsection{Artificial neural network modeling}

186

187

188

189

190

191

A neural network is a cluster of processing nodes (i.e., neurons) arranged in several layers and interconnected in a variety of topologies, following the paradigm of the functionality of the human brain. The successful development and implementation of an ANN model relies onto three principal conditions, each one with its own significance for the accuracy and efficiency of the developed model:

I. Correct identification of the input and output variables of the system, also called factors and responses, respectively. The selection of the principal factors (i.e., the ones with the greatest effect on the targeted response) from all possible candidates is a procedure that requires a minimum knowledge of the actual process. Its importance lies in the fact that the number and nature of the selected factors will affect, on the one hand, the number of required experimental data (i.e., the more factors considered, the greater the number of data required for an accurate model development), and on the other hand, will define whether important effects on the measured response have been omitted. In the case where prior knowledge on the process is completely absent, a small number of exploratory experiments can be carried out.

II. Definition of the experimental space and execution of a set of experiments for the acquisition of data. Given that the main factors of the process have been correctly 
identified and under the assumption that there exists a correlation between these factors and the targeted response of the system, an ANN model can identify this correlation on the basis of a set of experimental data. Evidently, the ability of the ANN to successfully correlate the input(s) (i.e., factors) and output(s) (i.e., response(s)) is directly proportional to the number of available data. On the other hand, the number of experiments that can be carried out is always subject to feasibility constraints (e.g., time and/or cost limitations, etc.) that may dictate the studied process. Hence, the second stage of the model development procedure. The Design of Experiments (DoE) approach enables to obtain a maximum amount of information from a given predefined experimental effort. Typical DoE strategies include full- or fractional-factorial designs,

217 III. Identification of the topology of the ANN: The structure of the network, in terms of the number and size of the hidden layers, as well as its characteristics (i.e., training algorithm, type of transfer functions, etc.), display a significant effect on the accuracy of the model. To identify these parameters, most studies follow a trial and error procedure where different topologies of the ANN are tested until satisfactory accuracy has been achieved. Note that the random initialization of the values of the network parameters (e.g., the neuron's weights) as well as of the data separation (c.f. next paragraph) must be taken into account during this procedure. 
225 Once the experimental data have been acquired and the factors/responses and architecture of 226 the ANN model have been defined, the development of the model proceeds via a series of 227 subsequent training (i.e., parametric identification) steps. In general, the accuracy of such 228 models is assessed in terms of different statistical magnitudes, such as the Mean Square Error, 229 MSE, or the correlation coefficient, $\mathrm{R}$, calculated on the basis of the comparison of the model responses and the respective experimental targets. These latter are divided into three distinct 231 subsets that serve for the training, validation and testing of the network, respectively. The 232 training data set is used for the identification of the model parameters while the test data set is used to assess the accuracy of the model on a set of data different than the ones used for the 234 training and validation processes. The validation data set is used to avoid overfitting 235 phenomena by monitoring the error (i.e., on this data set) throughout the training process. This 236 error normally decreases along with the training set error. An increase on the validation error 237 for a number of sequential epochs (i.e., training passes of the network) is an indication of overfitting that triggers the stopping of the training process, returning the network (i.e., the values of weights and biases) corresponding to the minimum value of the validation error. In the present work, the number of sequential epochs of increasing validation error before 241 stopping the training of the network was set to seven.

242 Among the various types of existing ANNs, the most commonly encountered in physicochemical 243 process modeling is the feed-forward (i.e., the responses of each layer are used as inputs of the 244 next layer) back-propagation (i.e., the measured error at the output layer is back transferred to 245 re-adjust the model parameter values) network, while the sigmoidal (e.g., logarithmic sigmoidal 246 or tangent hyperbolic sigmoidal) and linear transfer functions are widely applied on the hidden 
247 and output layers, respectively (Cheng \& Titterington, 1994; Haykin, 1994; Meireles et al., 2003;

248 Sivanandam et al., 2006). Additional details on the principles and the characteristics of neural 249 networks can be found in the relevant literature (Cheng \& Titterington, 1994; Haykin, 1994;

250 Meireles et al., 2003; Sivanandam et al., 2006).

251 Photocatalytic processes are greatly influenced by both catalyst properties and reaction 252 conditions. These effects are traditionally studied separately (see Table 1), probably due to the 253 complexity of assessing them simultaneously in a single study. An exception to this rule is the 254 work of Tanasa et al. (2013), who studied the system of Eosin Y dye photocatalytic degradation 255 using $\mathrm{ZnO} / \mathrm{SnO}_{2}$, taking into account the effects of crystallite size, surface area, absorption 256 edge, catalyst dose and total organic carbon values in their model that was developed on the 257 basis of a set of 547 experimental data. In addition, another commonly adopted practice is the 258 consideration of the irradiation time as a factor in the modeling of the percentage of 259 contaminant degradation (i.e., response). Given that the percentage of contaminant 260 degradation will normally increase with the reaction time, this approach finally leads to a rather 261 obvious correlation that, in turn, may come in the cost of missing other important effects of 262 different factors.

263 In the present work, a model development is presented that does not comply with the above 264 commonly adopted approaches. In order to combine the effects of both important stages of the 265 photocatalytic process, namely the catalyst synthesis and the photodegradation experiments, a 266 two-stage decoupled ANN model is developed where the response of the first network 267 becomes a factor for the second network. Thus, in the first stage of the model, the effects of 268 three operating conditions of the synthesis of $\mathrm{Ag} / \mathrm{ZnO}$ (i.e., nominal silver concentration, $\mathrm{pH}$ 
269 and reaction time, which were identified in Jasso-Salcedo et al., 2014 as the most significant 270 parameters of the process) on the actual amount of $\mathrm{Ag}$ attached on the surface of $\mathrm{ZnO}$ of the 271 synthesized photocatalyst were assessed in terms of an initial neural network, henceforth 272 called $\mathrm{ANN}_{1}$. In the second stage of this modelling framework, the effect of the actual amount 273 of $\mathrm{Ag}$ attached on the surface of $\mathrm{ZnO}, \mathrm{pH}$ of the medium, initial contaminant concentration and 274 wavelength of light on the photodegradation performance of the photocatalyst were assessed 275 in terms of a second neural network, $\mathrm{ANN}_{2}$. A direct dependence between the two networks 276 was established by directly introducing the response of $A N N_{1}$ as a factor of $A N N_{2}$. The 277 photodegradation performance (i.e., the response of $\mathrm{ANN}_{2}$ ) was evaluated in terms of an 278 apparent kinetic rate constant, $k_{\mathrm{app}}$, of the degradation reaction of BPA. This way, the 279 photocatalyst synthesis conditions were directly associated to its final photodegradation 280 performance, taking simultaneously into account the effects of the photodegradation 281 conditions. Note that, since the evaluation of the performance of the photocatalyst was based 282 on the rate of degradation of the contaminant, there was no need to consider the irradiation 283 time among the factors of the photodegradation process, which was kept constant for all 284 experiments and equal to $120 \mathrm{~min}$.

285 The experimental ranges of all factors of the two sub-models (i.e., $\mathrm{ANN}_{1}$ and $A N N_{2}$ ) are given in 286 Tables 2 and 3, respectively. Note that for the modification experiments of $\mathrm{ZnO}$, a central 287 composite design was employed. The photocatalyst concentration used for the degradation 288 tests was set to $1 \mathrm{~g} / \mathrm{L}$. A general schematic of the proposed modeling framework is shown in 289 Scheme 1. 

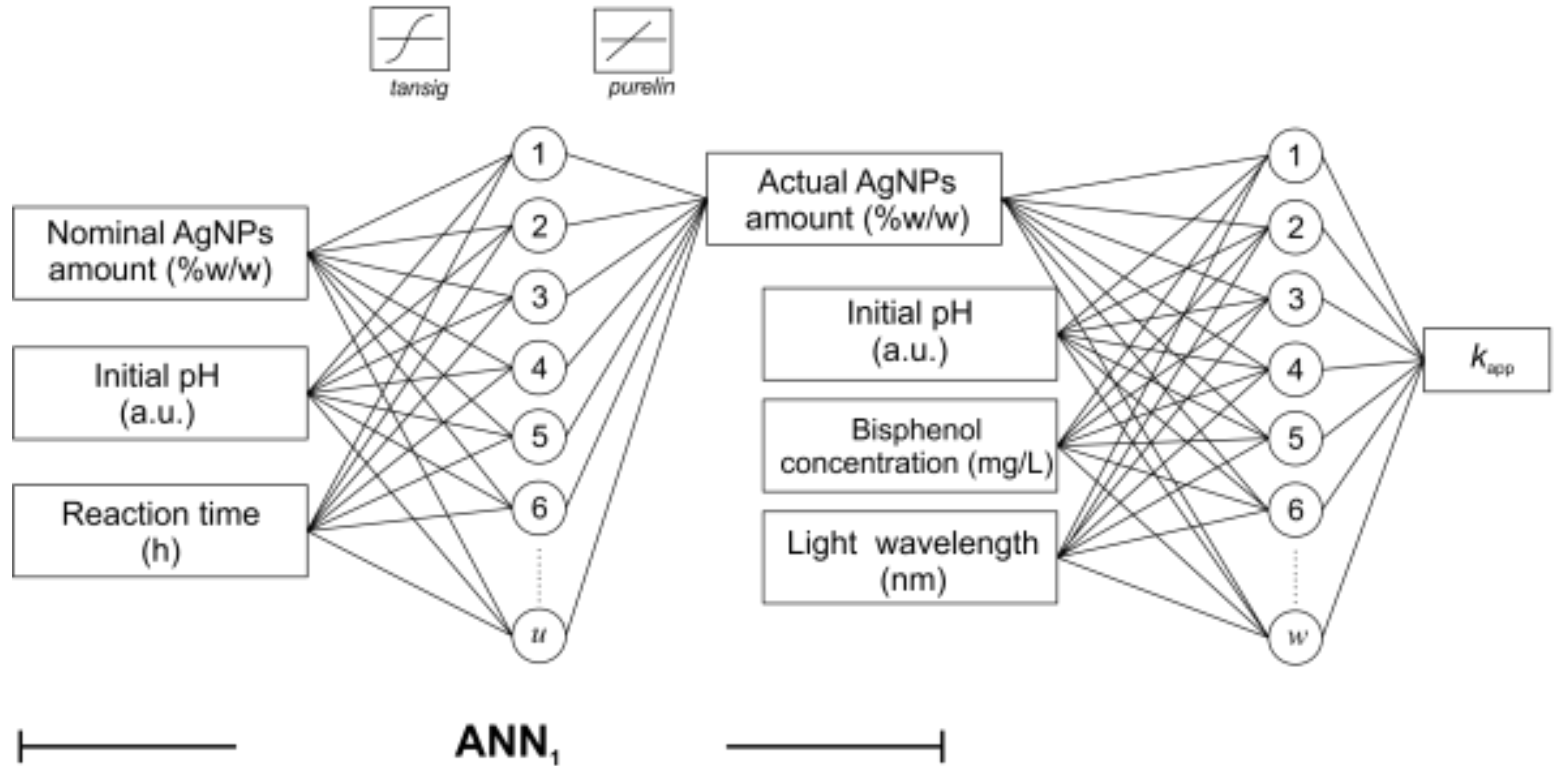

$\mathrm{ANN}_{1}$

Scheme 1. Description of the input/output characteristics and connecting points of the two

ANN models.

Table 2. Experimental range of the $\mathrm{Ag} / \mathrm{ZnO}$ photocatalyst synthesis conditions

\begin{tabular}{lll}
\hline Input variables & Photodeposition & Impregnation \\
\hline Nominal amount AgNPs (\% w/w) & $0.1-1$ & $0.1-5$ \\
Initial pH & $7-11$ & $7-11$ \\
Time (h) & $0.5-1$ & $2-5$ \\
\hline
\end{tabular}

Table 3. Experimental range of the photodegradation test conditions

Input variables

\begin{tabular}{ll}
\hline Initial $\mathrm{pH}$ & 2.8 to 10.5 \\
Actual amount AgNPs (\%w/w) & $0-1.2$ \\
Bisphenol-A (mg/L) & $10-40$ \\
Wavelength (nm) & $254,302,365$ and 450 \\
\hline
\end{tabular}




\subsubsection{Neural network structure}

299

300

301

302

303

304

305

306

A multi-layer feedforward network with Levenberg-Marquardt learning algorithm was used in this study. The experimental data corresponding to each model were randomly divided into training, validation and testing subsets (50\%, $25 \%$ and $25 \%$ of data, respectively). All data were normalized in the range [-1:1] prior to their introduction into the models.

The topology of the network models, denoted as (In:Hid:Out), corresponds to the numbers of neurons in the input, hidden and output layers, respectively. Several configurations of the network were tested to determine the best number of neurons in the hidden layer(s), based on the values of the MSE of the data sets. The MSE value between the ANN model predictions and the experimental data is typically calculated by the expression:

$M S E=\frac{\sum_{j=1}^{N}\left(y_{j}^{\bmod }-y_{j}^{\exp }\right)^{2}}{N}$

where the exponents 'mod' and 'exp' denote the outputs of the model (i.e., the responses) and the experiment (i.e., the targets), respectively and $\mathrm{N}$ is the total number of experimental data. Note that, in the present work, log-sigmoidal and linear transfer functions were used for hidden and output layers, respectively. The Neural Network Toolbox of the commercial software package MATLAB 8.3.0.532 (academic license) was used for the development of the models.

\subsection{Optimization study}

An ultimate purpose of process models, especially data-driven models, is their implementation in an optimization study in order to identify the combination of the different process conditions that will result to the desired properties/performance of the product/process under study. Among the plethora of different mathematical methods and techniques that have been 
319 developed for the treatment of optimization problems, evolutionary algorithms constitute a 320 powerful approach with specific advantages and disadvantages.

321 In general, an evolutionary algorithm (EA) is based on the principle of the continuous 322 improvement of a criterion (i.e., the optimization criterion) of the individuals of a population. 323 The initial population is composed of a large set of randomly selected individuals (e.g. 324 experimental conditions), which are characterized by a measured property or model response 325 (e.g., the degradation efficiency corresponding to each of these experiments). The population is 326 classified from the best individual to the worst, according to its corresponding value of the 327 criterion and depending on whether the problem is a minimization or a maximization one, and 328 is subsequently subjected to a series of cycles of improvement of this criterion. The best 329 individuals are combined to generate new ones that might perform better, while the worst 330 individuals are removed from the population after each cycle and the procedure continues until 331 the population has "evolved" to such a point where the desired convergence to an optimal has 332 been achieved. Detailed information on the theoretical basis of EAs for mono- and multi333 objective optimization, applied on physicochemical processes, can be found in the relevant 334 literature (Camargo et al., 2011; Fonteix et al., 1995; Viennet et al., 1996; Xi et al., 2013). EAs 335 have also been successfully implemented in the optimization study of the degradation of 336 phenol by a combined photocatalysis/electro-Fenton system (Khataee et al., 2014).

337 In the present work, an optimization study, on the basis of an EA, was also carried out in order 338 to identify the optimal catalyst synthesis and photodegradation conditions that would result to 339 the highest photodegradation rate of BPA. In accordance to the two-stage structure of the model, the optimization was also carried out in two consecutive steps, following an inverse 
341 direction. In this respect, an initial optimization problem was solved on the basis of $\mathrm{ANN}_{2}$ in 342 order to identify the different photodegradation conditions that would result to a maximum 343 degradation rate of BPA. Among these conditions, the $\mathrm{pH}, \mathrm{BPA}$ concentration and light 344 wavelength can be directly set to their optimized values, according to the results of this first 345 optimization study. On the other hand, the actual silver content of the photocatalyst depends 346 on the conditions of the photocatalyst synthesis process. Hence, a second optimization problem 347 was subsequently solved, via the implementation of an EA on the basis of $A N N_{1}$, in order to 348 identify the photocatalyst synthesis conditions that would result in the optimal amount of 349 attached AgNPs on the ZnO surface, as defined by the output of the first optimization run. Thus, 350 both important stages of the overall process (i.e., the synthesis of the photocatalyst and its 351 subsequent use in the photodegradation experiments) were taken into account and their 352 optimal conditions were identified in view of a maximal photodegradation rate of BPA. The 353 overall optimization approach is schematically depicted in Scheme 2. 


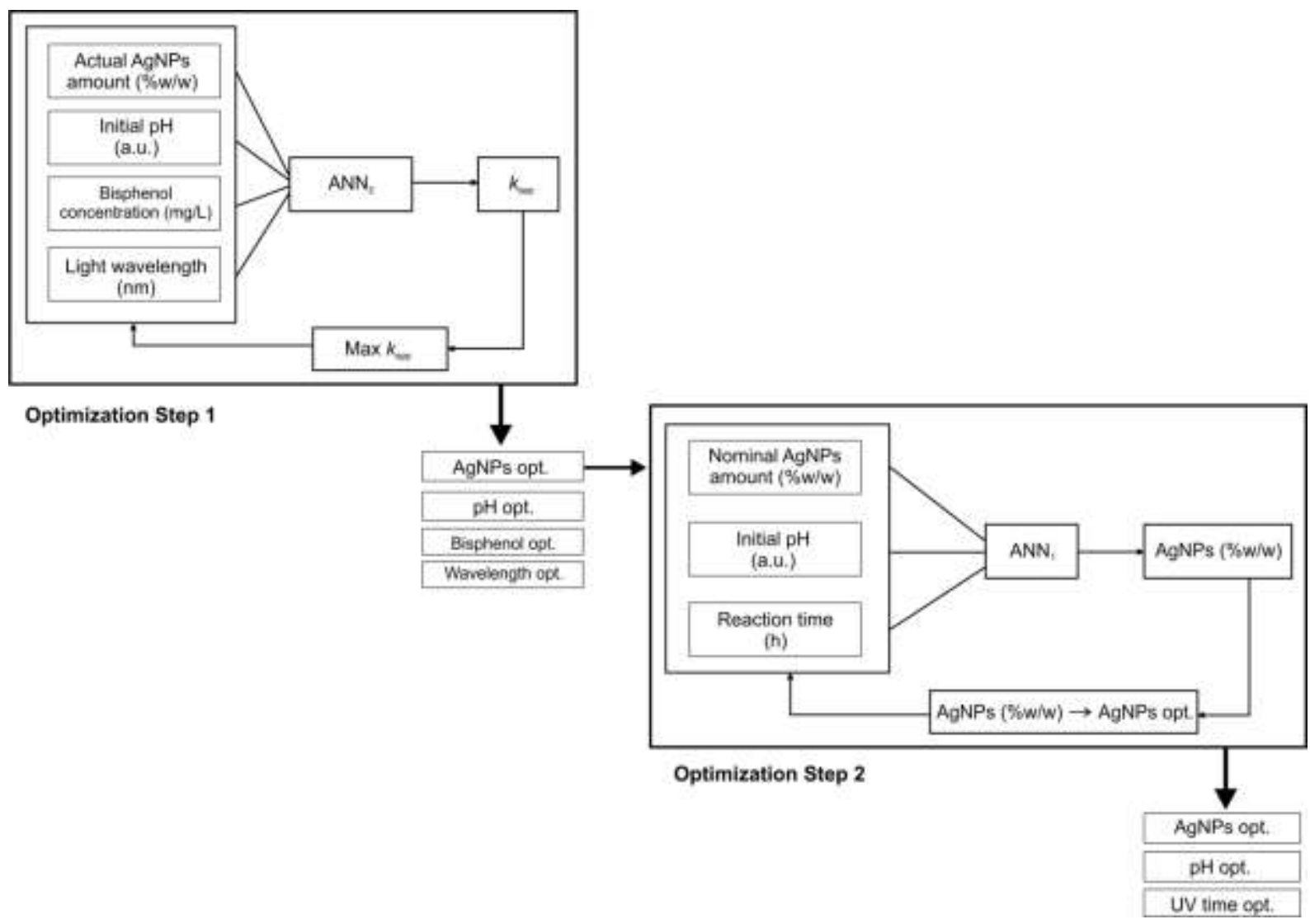

Scheme 2. Methodology used on the Evolutionary Algorithm - ANN coupled optimization approach on this study.

\section{Results and discussion}

The development of the two ANN sub-models was based on a total of 63 experiments for ANN $_{1}$ and 27 experiments for $\mathrm{ANN}_{2}$, divided into the two methods of the photocatalyst synthesis (i.e., PD and IMP methods) as shown in Tables 4 and 5. On the basis of these experimental data, the identification of the optimal network topologies initially took place and subsequently the ANN models were tested and validated before their implementation into the optimization study. 
365 Table 4. Experimental conditions for the synthesis of $\mathrm{Ag} / \mathrm{ZnO}$ photocatalyst and actual amount of $\mathrm{Ag}$ attached to the $\mathrm{ZnO}$ surface as measured 366 experimentally and predicted theoretically by the $\mathrm{ANN}_{1}$ models

\begin{tabular}{|c|c|c|c|c|c|c|c|c|c|}
\hline $\begin{array}{l}\text { Nominal } \\
\mathrm{Ag} \% \mathrm{w} / \mathrm{w}\end{array}$ & $\mathrm{pH}$ & $\begin{array}{c}\text { Reaction time } \\
(\min )\end{array}$ & $\begin{array}{c}\text { Attached Ag \%w/w } \\
\text { (experimental) }\end{array}$ & $\begin{array}{c}\text { Attached Ag \%w/w } \\
\left(\mathrm{ANN}_{1} \text { model) }\right.\end{array}$ & $\begin{array}{l}\text { Nominal } \\
\mathrm{Ag} \% \mathrm{w} / \mathrm{w}\end{array}$ & $\mathrm{pH}$ & $\begin{array}{c}\text { Reaction time } \\
(\min )\end{array}$ & $\begin{array}{c}\text { Attached Ag \%w/w } \\
\text { (experimental) }\end{array}$ & $\begin{array}{l}\text { Attached Ag \%w/w } \\
\left(\mathrm{ANN}_{1} \text { model) }\right.\end{array}$ \\
\hline \multicolumn{5}{|c|}{ Photodeposition method } & \multicolumn{5}{|c|}{ Impregnation method } \\
\hline 0.3573 & 7 & 30 & 0.320 & 0.327 & 0.1072 & 7 & 60 & 0.100 & 0.116 \\
\hline 0.3573 & 7 & 60 & 0.342 & 0.348 & 0.1072 & 7 & 120 & 0.106 & 0.121 \\
\hline 0.1073 & 7 & 30 & 0.082 & 0.084 & 0.1072 & 7 & 300 & 0.094 & 0.094 \\
\hline 0.1073 & 7 & 60 & 0.107 & 0.102 & 1.0623 & 7 & 60 & 1.179 & 1.179 \\
\hline 1.0623 & 7 & 30 & 0.991 & 0.920 & 1.0623 & 7 & 120 & 1.203 & 1.203 \\
\hline 1.0623 & 7 & 60 & 1.093 & 1.099 & 1.0623 & 7 & 300 & 0.820 & 0.807 \\
\hline 0.3573 & 9 & 30 & 0.358 & 0.356 & 5.095 & 7 & 60 & 0.521 & 0.522 \\
\hline 0.3573 & 9 & 60 & 0.375 & 0.378 & 5.095 & 7 & 120 & 0.585 & 0.773 \\
\hline 0.1073 & 9 & 30 & 0.062 & 0.062 & 5.095 & 7 & 300 & 0.668 & 0.671 \\
\hline 0.1073 & 9 & 60 & 0.074 & 0.075 & 0.1072 & 9 & 60 & 0.099 & 0.093 \\
\hline 1.0623 & 9 & 30 & 1.170 & 1.104 & 0.1072 & 9 & 120 & 0.110 & 0.110 \\
\hline 1.0623 & 9 & 60 & 1.132 & 1.130 & 0.1072 & 9 & 300 & 0.096 & 0.100 \\
\hline 0.3573 & 11 & 30 & 0.454 & 0.451 & 1.0623 & 9 & 60 & 0.970 & 1.012 \\
\hline 0.3573 & 11 & 60 & 0.426 & 0.397 & 1.0623 & 9 & 120 & 1.192 & 1.188 \\
\hline 0.1073 & 11 & 30 & 0.091 & 0.092 & 1.0623 & 9 & 300 & 1.194 & 1.193 \\
\hline 0.1073 & 11 & 60 & 0.116 & 0.121 & 5.095 & 9 & 60 & 0.423 & 1.044 \\
\hline 1.0623 & 11 & 30 & 1.183 & 1.182 & 5.095 & 9 & 120 & 0.494 & 0.336 \\
\hline 1.0623 & 11 & 60 & 1.147 & 1.137 & 5.095 & 9 & 300 & 0.571 & 0.580 \\
\hline 0.3573 & 7 & 45 & 0.320 & 0.325 & 0.1072 & 11 & 60 & 0.116 & 0.105 \\
\hline 0.1073 & 9 & 45 & 0.074 & 0.071 & 0.1072 & 11 & 120 & 0.121 & 0.121 \\
\hline 1.0623 & 9 & 45 & 1.132 & 1.132 & 0.1072 & 11 & 300 & 0.116 & 0.120 \\
\hline 0.3573 & 9 & 45 & 0.362 & 0.365 & 1.0623 & 11 & 60 & 0.239 & 0.239 \\
\hline 0.1073 & 7 & 45 & 0.096 & 0.096 & 1.0623 & 11 & 120 & 0.366 & 0.561 \\
\hline 0.1073 & 11 & 45 & 0.103 & 0.102 & 1.0623 & 11 & 300 & 1.108 & 1.101 \\
\hline 1.0623 & 7 & 45 & 1.050 & 1.054 & 5.095 & 11 & 60 & 0.374 & 0.375 \\
\hline
\end{tabular}




\begin{tabular}{|c|c|c|c|c|c|c|c|c|c|}
\hline 1.0623 & 11 & 45 & 1.162 & 1.161 & 5.095 & 11 & 120 & 0.389 & 1.144 \\
\hline 0.3573 & 9 & 45 & 0.371 & 0.365 & 5.095 & 11 & 300 & 0.498 & 0.503 \\
\hline 0.3573 & 9 & 45 & 0.368 & 0.365 & 1.0623 & 9 & 120 & 1.169 & 1.188 \\
\hline 0.3573 & 9 & 45 & 0.385 & 0.365 & 1.0623 & 9 & 120 & 1.223 & 1.188 \\
\hline 0.3573 & 9 & 45 & 0.357 & 0.365 & 1.0623 & 9 & 120 & 1.023 & 1.188 \\
\hline \multirow[t]{2}{*}{0.3573} & 9 & 45 & 0.362 & 0.365 & 1.0623 & 9 & 120 & 1.179 & 1.188 \\
\hline & & & & & 1.0623 & 9 & 120 & 1.167 & 1.188 \\
\hline
\end{tabular}

367

368

\subsection{Selection of optimal network topology}

370 The selection of the network topology was based on a typical trial and error approach where the number of neurons of the hidden

371 layer(s) was varied in the range 1-20 (i.e., for a single hidden layer) and 1:1-10:10 (i.e., for two hidden layers) and the accuracy of the

372 developed model was assessed in terms of the MSE values between the model predictions and the experimental data. An example

373 of the results obtained by this procedure is shown in Figure 1 for the $A N N_{1}$ model and the PD method. In this Figure, the ten best

374 (i.e., corresponding to the lowest MSE values) network configurations are shown in a MSE-increasing order. Note that the errors

375 corresponding to all data, validation and testing data sets are shown in order to verify the consistency of the model performance vis-

376 à-vis the different data sets. Each network topology was run 50 times (i.e., 50 different ANNs with the same topology were

377 developed and evaluated) and the average value of MSE was used for comparison, in order to avoid random correlation effects. 
Table 5. Experimental conditions of bisphenol-A degradation and apparent kinetic rate constant $k_{\text {app }}$ used on the

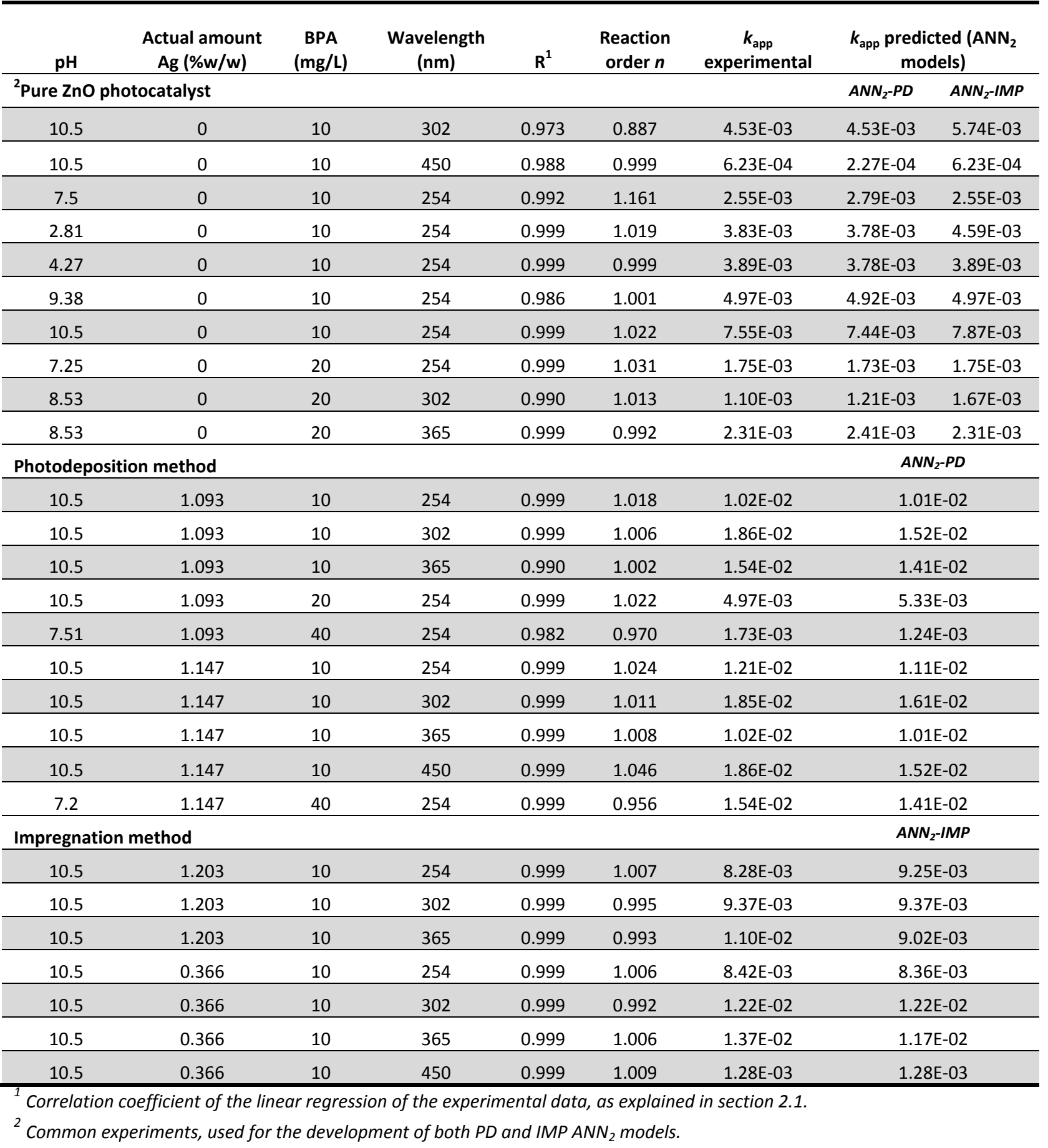




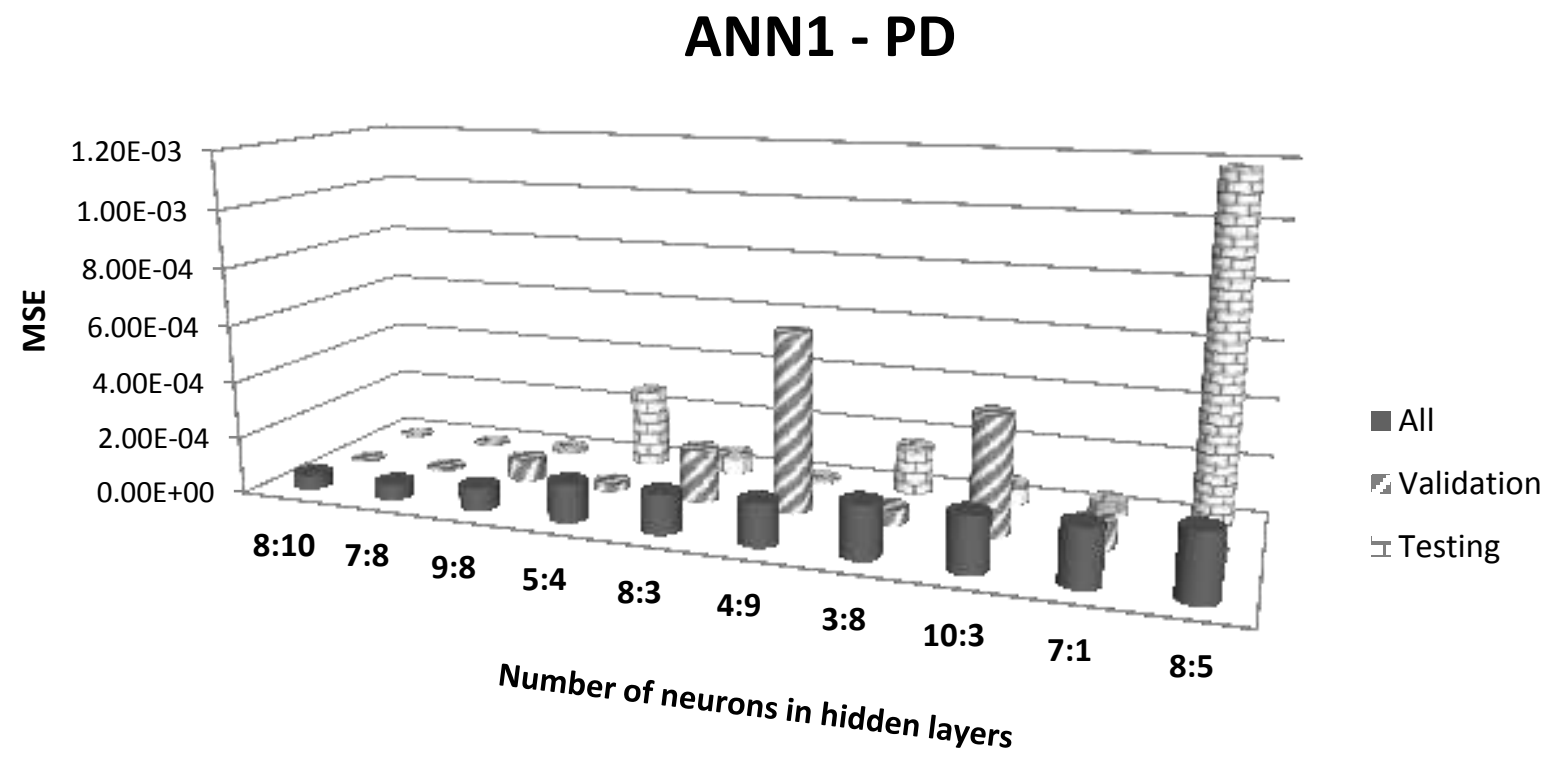

Figure 1. MSE for all data, validation and test datasets as function of neurons in the hidden layer on the network topology for the developed ANN1 model (photodeposition method).

The numerical data corresponding to Figure 1, as well as the data corresponding to the other three models (i.e., $A N N_{1}-I M P, A N N_{2}-P D$ and $A N N_{2}-I M P$ ) are given in Table $S .1$ of the supplementary material section. The network topologies that were retained according to this procedure are shown in Table 6:

Table 6. Network topology of the developed models

\begin{tabular}{c|cc}
\hline \multicolumn{2}{c}{ Photodeposition - PD } & Impregnation - IMP \\
\hline ANN $_{1}$ & $3: 8: 10: 1$ & $4: 9: 8: 1$ \\
ANN $_{2}$ & $3: 10: 10: 1$ & $4: 8: 10: 1$ \\
\hline
\end{tabular}




\subsection{Evaluation of the ANN models}

395 Neural network models are typically assessed, in terms of their accuracy in simulating the experimental data, by plotting the model response with respect to the experimental measurements. A comparison of the points of such plots with the diagonal (i.e., the linear curve corresponding to $y=x$ ) reveals the accuracy of the developed model. Figures 2 and 3 depict such plots for the $\mathrm{ANN}_{1}$ and $\mathrm{ANN}_{2}$ models, respectively. In these plots, the all data and test data sets are shown in order to reveal the accuracy of the model with respect to all available data,

401 including the training data for which a higher accuracy is expected, as well as with respect only 402 to the test data, which represent a subset of the available data that has not been used during 403 the model training process. The value of the correlation coefficient, $\mathrm{R}$, of the linear regression 404 of the data is also shown on the plots. It can be seen that the $\mathrm{ANN}_{1}$ model exhibits higher 405 accuracy than the $\mathrm{ANN}_{2}$ model, which seems to under-predict the experimental values at the 406 high-values domain of $k_{\text {app }}$ but, in general, remains quite accurate as well. This can be partially 407 attributed to the smaller size of available experimental data for the second model. The values 408 of the experimental data used for the development of the models and the respective model 409 predictions are also given in Tables 4 and 5. Note that, for the training of the models of the 410 photodegradation experiments, $\mathrm{ANN}_{2}$, the target values of the experimental apparent rate 411 constant were transformed to their log values, in order to avoid a variation over several orders 412 of magnitude. Nevertheless, in all graphical and numerical results presented in this paper, the 413 original non-transformed values are shown for reasons of simplicity. 

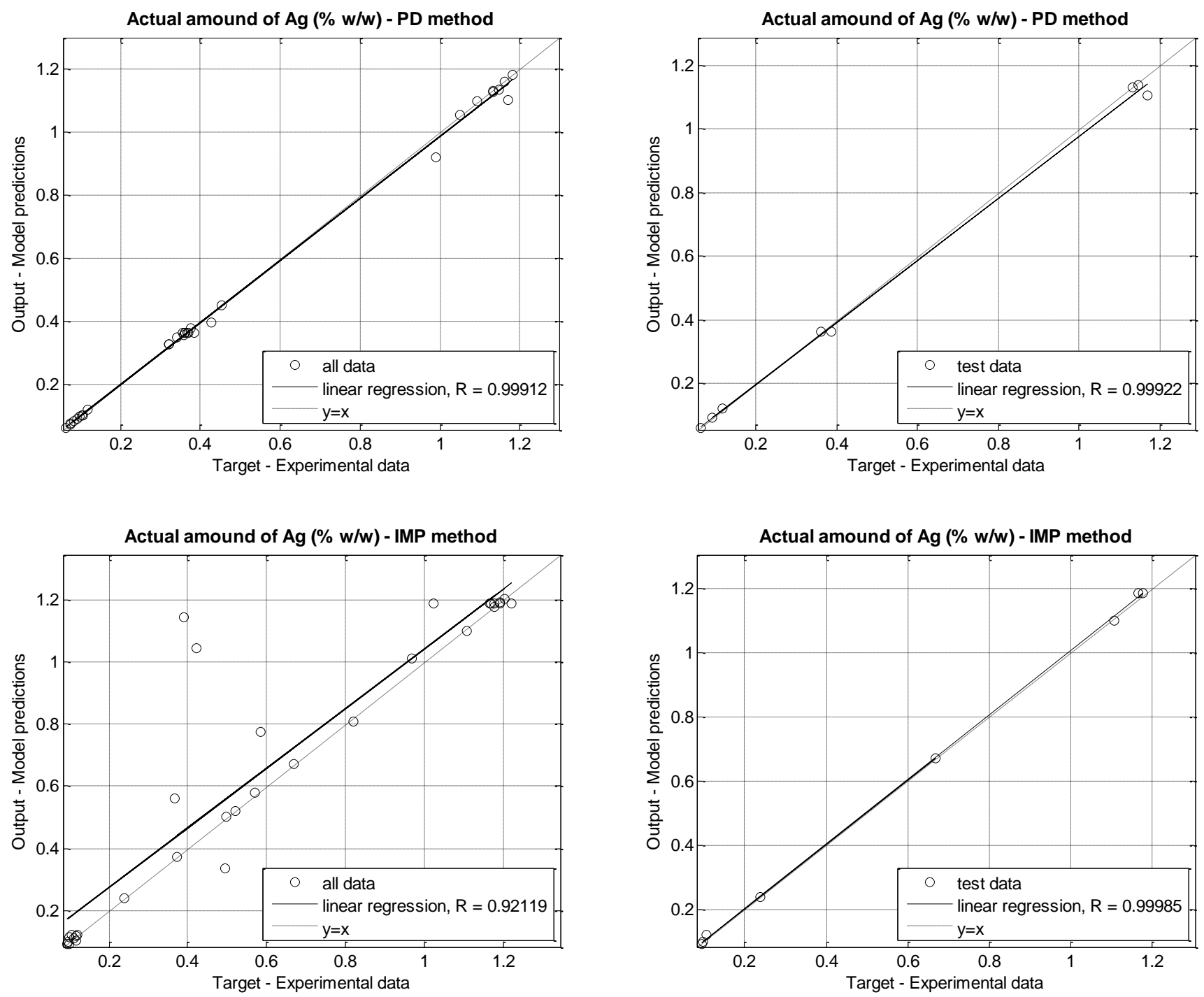

414 Figure 2. Regression plots of the experimental data (all data and test data sets) versus model predicted values for 415 the developed neural network models $\mathrm{ANN}_{1}-\mathrm{PD}$ (top) and $\mathrm{ANN}_{1}$-IMP (bottom).

416 

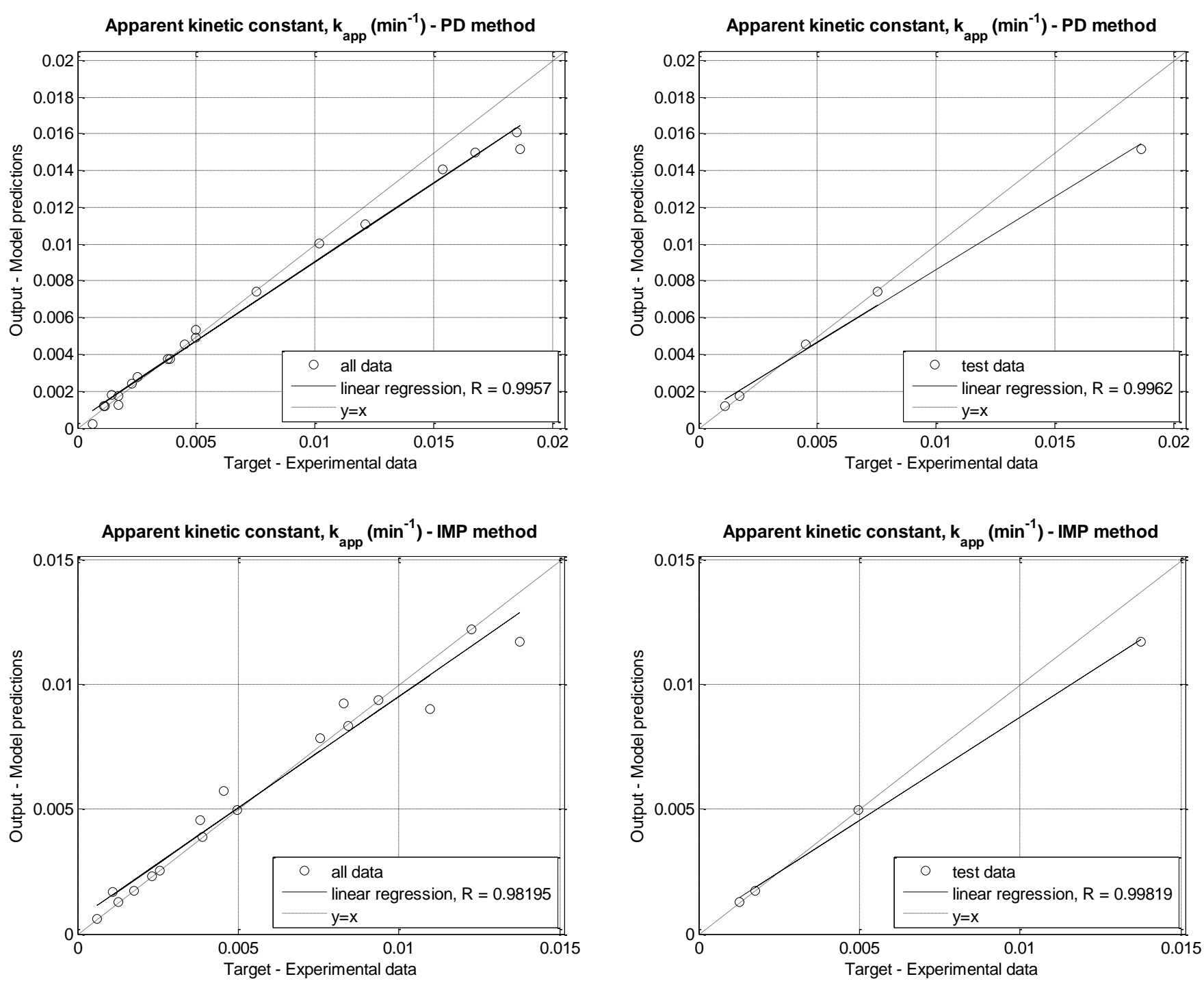

417 Figure 3. Regression plots of the experimental data (all data and test data sets) versus model predicted values for 418 the developed neural network models $\mathrm{ANN}_{2}-\mathrm{PD}$ (top) and $\mathrm{ANN}_{2}-\mathrm{IMP}$ (bottom). 


\subsection{Analysis of the model results}

421 Once the ANN models have been successfully developed and validated, they can be directly 422 implemented, using input values that do not necessarily correspond to the experimentally 423 tested conditions, in order to assess the effect of the different conditions of each sub-process

424 (i.e., the catalyst synthesis and the degradation tests) to the respective response of interest (i.e., 425 the actual amount of attached $\mathrm{Ag}$ on the photocatalyst and the apparent degradation rate 426 constant, respectively). In this respect, Figures $4 \mathrm{a}-4 \mathrm{f}$ show the effect of $\mathrm{pH}$ and actual silver 427 content on the degradation rate of BPA, under different conditions of BPA amount and light 428 wavelength, as produced by the $\mathrm{ANN}_{2}-\mathrm{PD}$ model. An initial observation is that the response 429 surfaces are highly irregular, not displaying a clear increasing or decreasing effect. It should be 430 noted at this point that the presented curves can only serve to acquire a general idea about the 431 different trends that the model might display with respect to the variation of certain inputs. 432 They cannot be used to identify specific points or values with accuracy since the viewpoint angle 433 and the graphical interpolation used for their creation may lead to errors.

434 Concerning the effect of $\mathrm{pH}$, it can be seen that, as $\mathrm{pH}$ increases the values of $k_{\text {app }}$ initially 435 increase, reaching a maximum within the range of $\mathrm{pH}$ values $6-9$, and then decrease. This effect 436 is particularly obvious in Figures $4 \mathrm{~d}-4 \mathrm{f}$. The $\mathrm{pH}$ is an important factor in photocatalysis since it 437 affects the surface charges of both the photocatalyst and the contaminant as follows. In the 438 vicinity above neutral $\mathrm{pH}_{\mathrm{PZC}}=8.3$ (i.e., value of neutral surface charges for $\mathrm{ZnO}$ ), hydroxyl439 compounds of zinc such as $\mathrm{ZnOH}^{+}, \mathrm{Zn}(\mathrm{OH})_{2}$, and $\mathrm{Zn}(\mathrm{OH})_{3}{ }^{-}$are formed in the solution and they 440 interact with the undissociated BPA $\left(\mathrm{HO}-\mathrm{C}_{15} \mathrm{H}_{14}-\mathrm{OH}\right)$ toward its oxidation. Below this value, an 
441 increase in the hydroxyl ion $(\mathrm{OH})$ concentration and, subsequently, to the hydroxyl radical $442(\bullet \mathrm{OH})$ concentration leads to the oxidation of BPA. Comparable results have been reported on 443 the degradation efficiency of BPA by pure ZnO by Rahman et al. (2005), who reported $80 \%$ 444 degradation efficiency of $100 \mathrm{mg} / \mathrm{L}$ of BPA in the $\mathrm{pH}$ range of 2 to 8.5 , and a significant decrease 445 to $60 \%$ at pH 11. Also, Clament Sagaya Selvam et al. (2013) reported the complete degradation 446 of $200 \mathrm{mg} / \mathrm{L}$ of BPA at $\mathrm{pH} 8$ and a subsequent decrease of the degradation efficiency at $\mathrm{pH}$ $447 \quad$ values above 9.

448
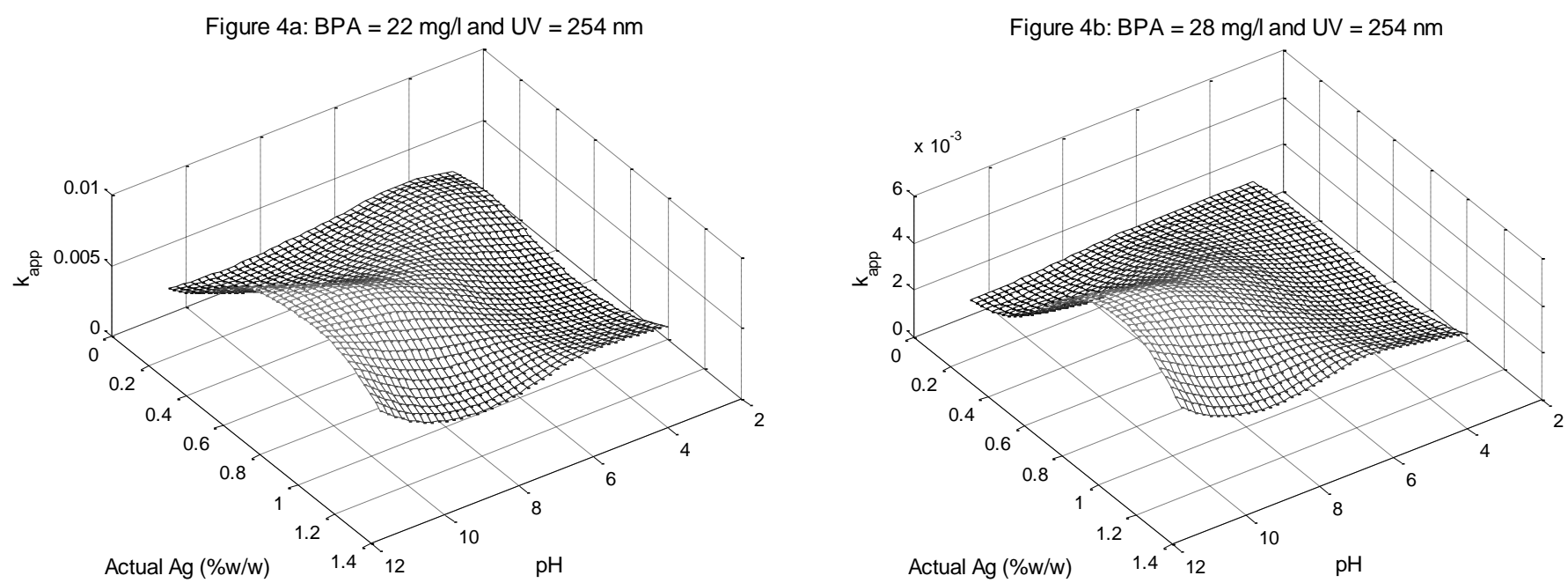

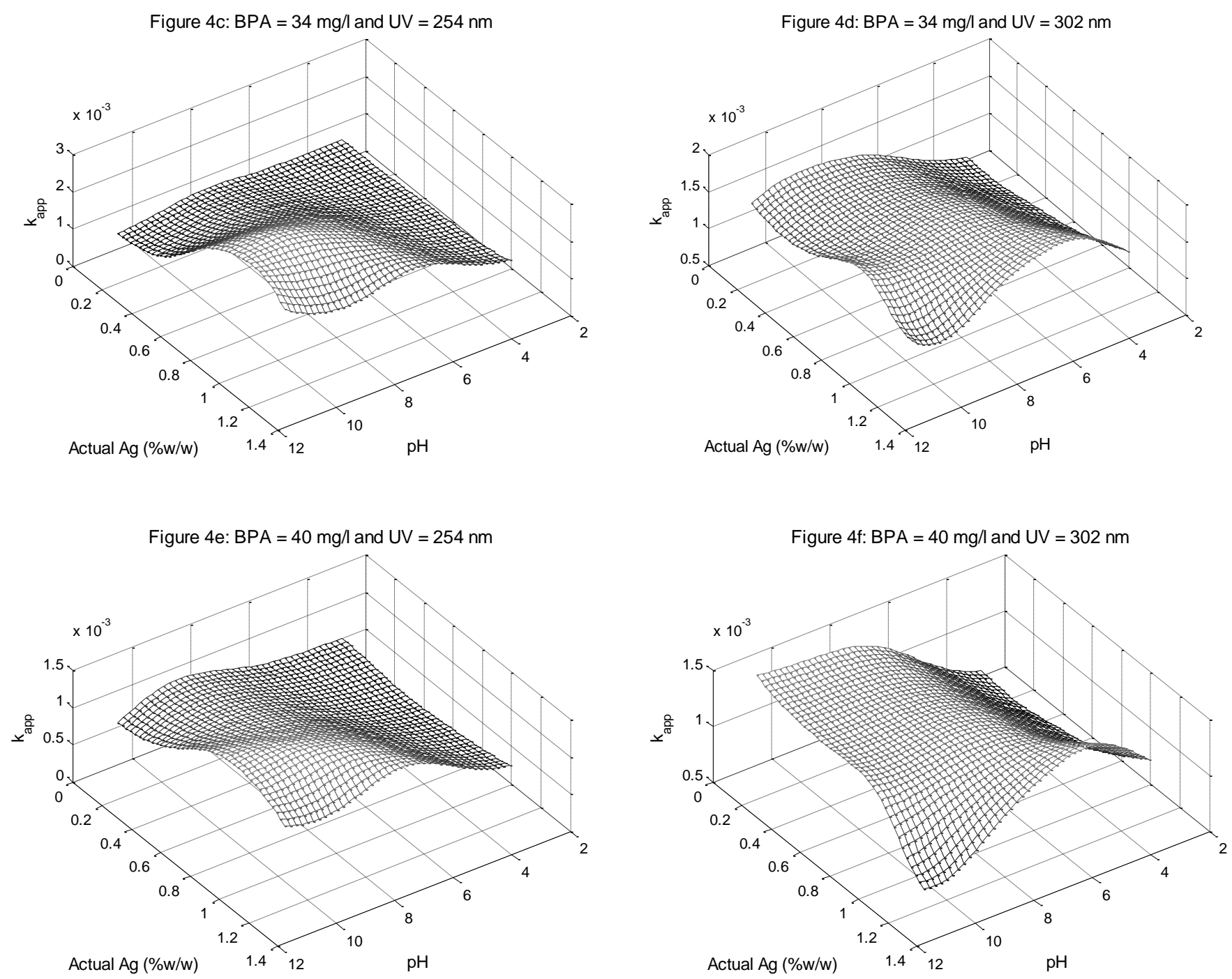

449 Figure 4: Effect of $\mathrm{pH}$ and actual silver content (\% w/w) on the apparent degradation rate constant under different 450 conditions of BPA content and UV wavelength, as simulated by the $\mathrm{ANN}_{2}-\mathrm{PD}$ model.

451 On the other hand, the effects of BPA concentration and UV wavelength are not so evident.

452 Nevertheless, the initial contaminant concentration seems to display an inversely proportional

453 effect on the values of $k_{\text {app }}$, since they seem to be decreasing at higher BPA concentrations. This

454 effect can be partially explained by an absorbance of the UV light (at 255 and $277 \mathrm{~nm}$ ) by BPA

455 molecules. This way, the activation of the photocatalyst surface is reduced thus producing a

456 screening effect of the BPA molecules towards the UV light penetration. 
457 A similar effect for all factors can be observed for the impregnation model, $\mathrm{ANN}_{2}$-IMP, as well.

458 Four representative surfaces are shown in Figures $5 a-5 d$, under different conditions of BPA

459 content and light wavelength. As can be seen, the value of $k_{\text {app }}$ displays once more a maximum

460 around the middle of the $\mathrm{pH}$ and BPA concentration domains and decreases with increasing BPA

461 concentration.
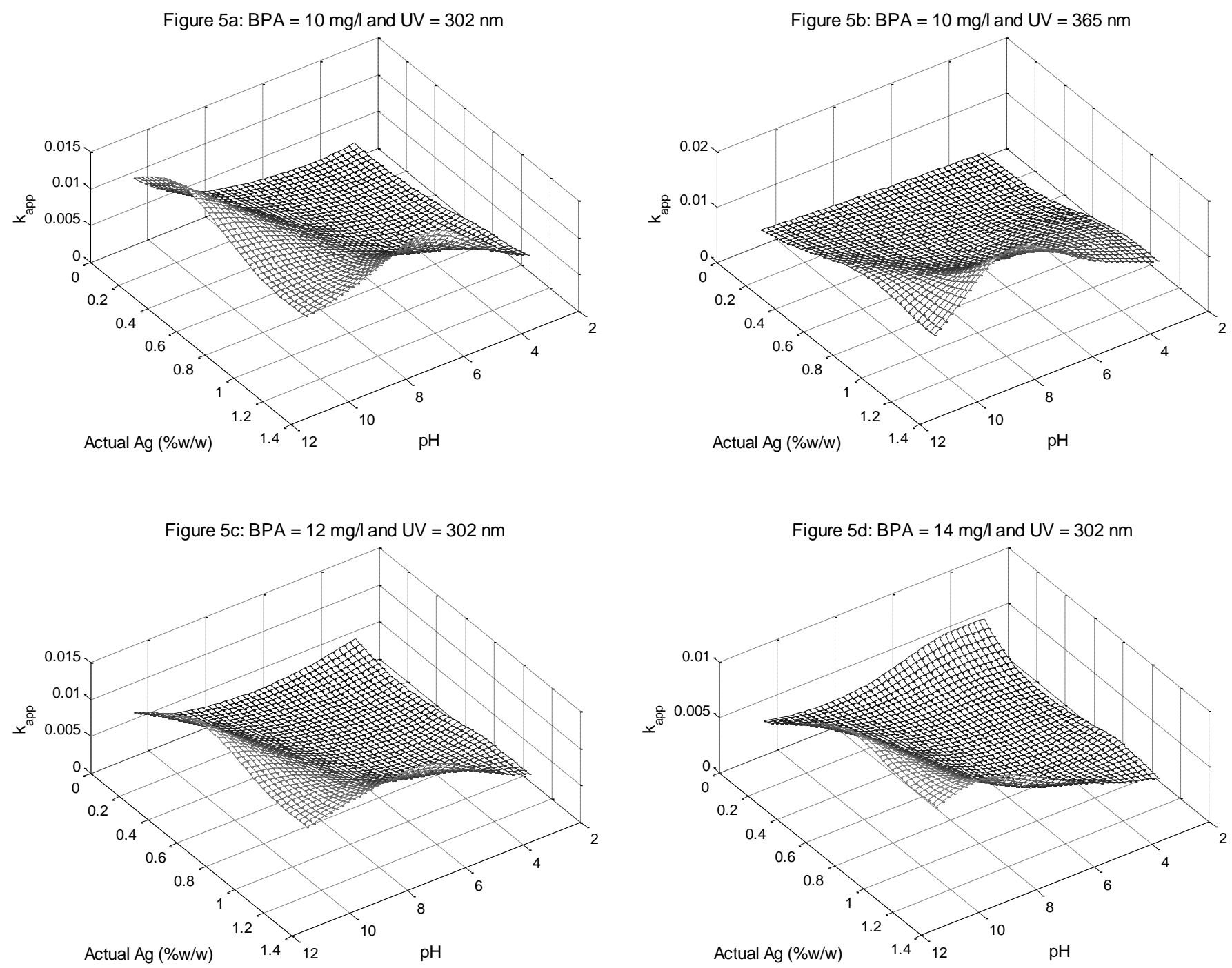

Figure 5: Effect of $\mathrm{pH}$ and actual silver content $(\% \mathrm{w} / \mathrm{w})$ on the apparent degradation rate constant under different conditions of BPA content and UV wavelength, as simulated by the $\mathrm{ANN}_{2}$-IMP model. 
464 Concerning the first model, $\mathrm{ANN}_{1}$, a similar analysis can be made on the effects of the catalyst 465 synthesis conditions on the overall functionalization degree, FD, defined as the ratio of the 466 actual amount of silver on the catalyst particles over the nominal amount of silver used during 467 the catalyst synthesis. In Figures $6 a$ and $6 \mathrm{~b}$, two surface plots, similar to the ones previously 468 depicted for $\mathrm{ANN}_{2}$, are shown corresponding to the photodeposition method and to two 469 different values of nominal amount of silver. The corresponding plots for the impregnation 470 method are depicted in Figures $6 \mathrm{c}$ and $6 \mathrm{~d}$. As can be seen, there is no significant variation of FD 471 with respect to $\mathrm{pH}$ and time when the photodeposition method is implemented. On the other 472 hand, the reaction time seems to have an overall positive effect on the FD values and to display 473 a maximum around $150 \mathrm{~min}$, when the impregnation method is used.

474 The effect of $\mathrm{pH}$ seems to vary with the time of reaction and the nominal AG amount, especially 475 for the photodeposition method. At the same time, an excess nominal amount of silver does not 476 seem to display a positive effect on the functionalization degree when the impregnation 477 method is implemented, which is particularly obvious in Figure $6 \mathrm{~d}$. It should be noted at this 478 point that the experimental values of FD that are higher than 1 are due to experimental 479 sampling and titration errors, as explained in (Jasso-Salcedo et al., 2014). As a consequence it is 480 normal that the developed neural network model, which was trained on the basis of these 481 experimental values, provides responses that result in values of FD higher than 1. 

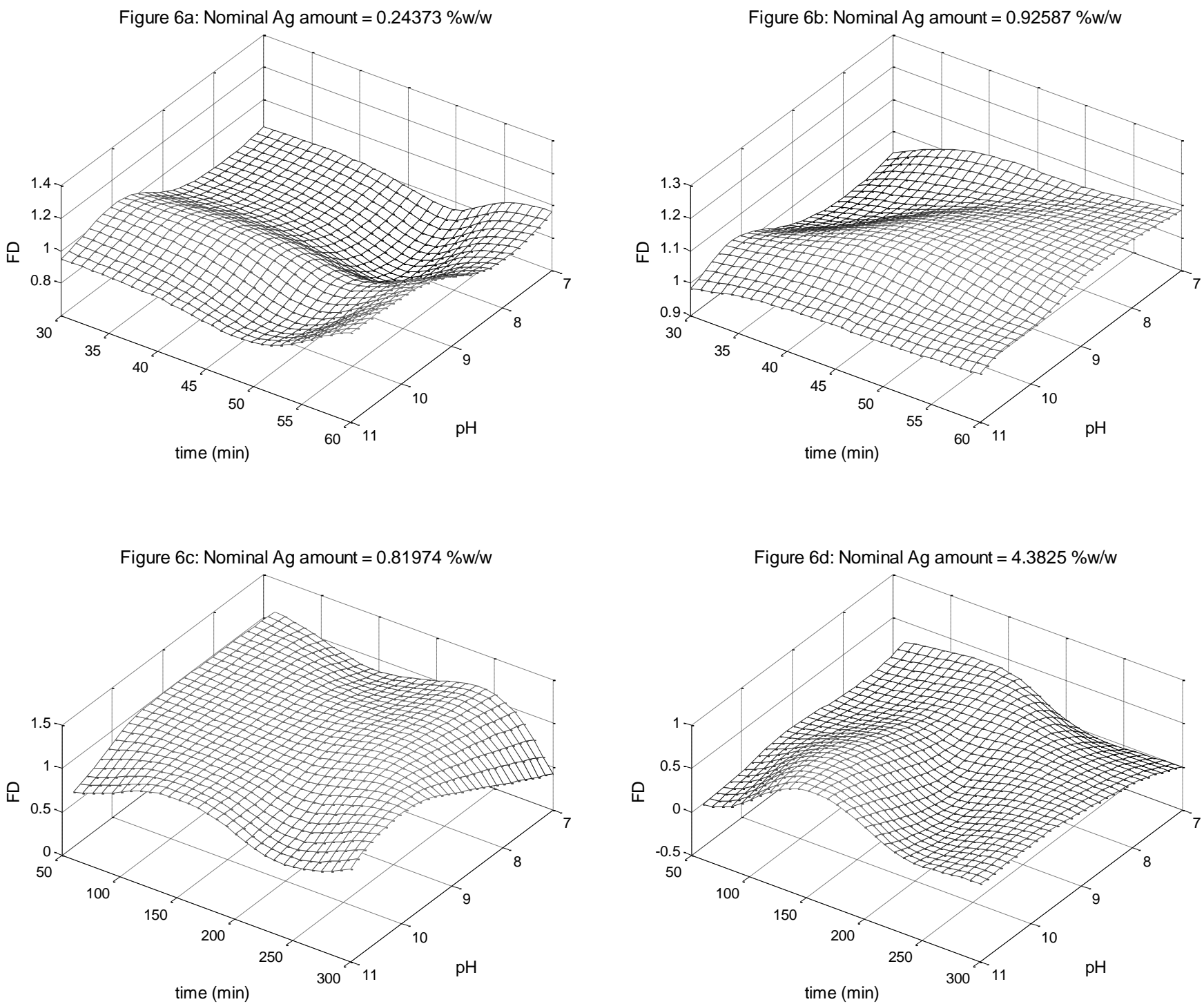

482

Figure 6: Effect of $\mathrm{pH}$ and nominal silver content (\% w/w) on the functionalization degree (i.e., the ratio of actual to nominal amount of $\mathrm{Ag}$ ) under different values of nominal $\mathrm{Ag}$ amount as simulated by the $\operatorname{ANN}_{1}-\mathrm{PD}(\mathrm{a}, \mathrm{b})$ and $\mathrm{ANN}_{1^{-}}$ $484 \operatorname{IMP}(\mathrm{d}, \mathrm{c})$ models.

485

\subsection{Optimization step 1 - apparent kinetic rate constant, $\boldsymbol{k}_{\mathrm{app}}$}

487 Given the nature of the photodegradation process and the definition of the output of the process on the basis of the apparent kinetic rate constant of a first-order degradation reaction, it becomes evident that the desired value of this constant is the maximal possible value it could 
attain, as this will lead to a faster degradation of a maximum amount of BPA. Hence, the first

491 step of the optimization study, on the basis of $\mathrm{ANN}_{2}$, was the solution of a maximization

492 problem in terms of the conditions of the photodegradation process, namely the actual amount

493 of attached AgNPs, the $\mathrm{pH}$, the BPA concentration and the light wavelength. The deployment of

494 an EA for the solution of this problem for both methods of photocatalyst synthesis resulted in

495 the sets of optimal conditions shown in Table 7. Note that, for the EA algorithm, the following

496 parameters were used: the size of the population was set to 1000 individuals, the survival rate

497 was set to $70 \%$ and the mutation rate to $10 \%$. The program was entirely written and run on

498 MATLAB (version 8.3.0.532; academic license) while the convergence of the algorithm was

499 tested in terms of a tolerance in the relative difference between the best and worst criterion

500 values of each generation, set in the order of $1 \%$. The CPU time required for every optimization

501 run was in the order of $30 \mathrm{~s}$ on a $2 \times 2.4 \mathrm{GHz}$ Intel ${ }^{\circledR}$ Xeon ${ }^{\circledR}$ Workstation.

502

503

Table 7: Results of the first optimization step on the maximization of $k_{\text {app }}$

Optimal photodegradation conditions for the photodeposition method $\left(k_{\mathrm{app}, \max }=\mathbf{0 . 0 3 8 3} \mathrm{min}^{-1}\right)$

$\begin{array}{cccc}\text { Actual amount } \mathrm{Ag}, \% \mathrm{w} / \mathrm{w} & \mathrm{pH} \text { (initial value) } & \text { BPA concentration, } \mathrm{mg} / \mathrm{L} & \text { Wavelength, } \mathrm{nm} \\ 1.10 & 6.7 & 10.8 & 330\end{array}$

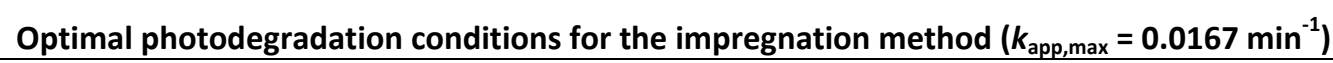

Actual amount $\mathrm{Ag}, \% \mathrm{w} / \mathrm{w}$

0.78 $\mathrm{pH}$ (initial value)

10.1
BPA concentration, $\mathrm{mg} / \mathrm{L}$

10.2
Wavelength, $\mathrm{nm}$ 358

505 In order to follow the evolution of the optimization and to verify its convergence around one (or more) optimal(s), one can plot the positions of a number of 'best' (i.e., top ranked) individuals, corresponding to an equal number of optimal conditions, along different generations of the optimization procedure. In Figures 7a-7d, a set of 50 optimal conditions is depicted, as calculated by the EA optimization of the $A N_{2}-P D$ model. 

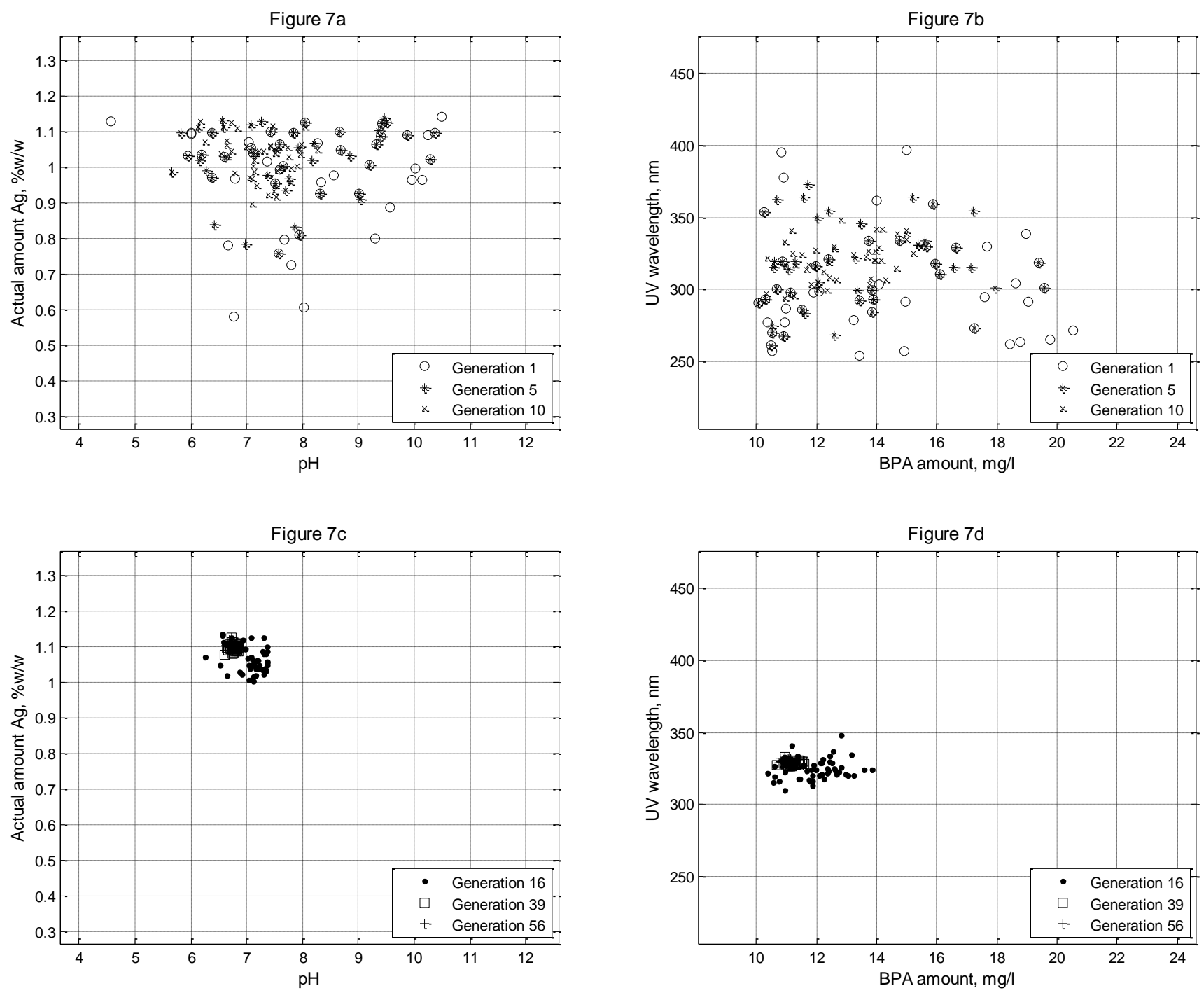

511 Figure 7: Presentation of the 50 optimal conditions in terms of the actual amount of $\mathrm{Ag}$ and $\mathrm{pH}(\mathrm{a}, \mathrm{c})$ and the UV 512 wavelength and the BPA amount (b, d), as predicted by the EA optimization on the basis of the ANN ${ }_{2}$-PD model 513 after 1, 5 and 10 generations (a, b) as well as after 16, 39 and 56 generations (c, d).

514 Since there are four different factors for this model, two plots are produced for each 515 generation, one corresponding to the optimal values of the actual amount of silver and $\mathrm{pH}$ and 516 another corresponding to the optimal values of the UV wavelength and the initial BPA amount.

517 The same Figures have been plotted for three different generations at the early stages of the 518 optimization (i.e., generations 1, 2 and 10, cf. Figures 7a and 7b) as well as for three generations 
519 at the middle and final stages of the optimization (i.e., generations 16, 39 and 56, cf. Figures 7c 520 and $7 d$ ). This illustration reveals the convergence of the optimization around a unique set of

521 optimal conditions (cf. Table 7). In this specific case, the convergence was achieved after 56

522 iterations, according to the convergence criterion defined earlier in this Section. Note that the

523 predicted optimal value of $k_{\mathrm{app}}$ is significantly increased with respect to the experimentally

524 measured values.

525 Figures 8a-8d present the corresponding plots of the same optimization problem but for the 526 impregnation method (i.e., on the basis of $\mathrm{ANN}_{2}-\mathrm{IMP}$ ). In this case, several local maxima seem to 527 exist so the optimization does not converge around one single set of optimal conditions. The 528 conditions reported in Table 7 are the ones that lead to the maximum attaint value of the 529 apparent rate constant and correspond to the set of points located on the right in Figure 8c and 530 on the top left in Figure 8d. In any case, this method seems to lead to significantly lower optimal 531 values of the rate constant, in comparison to the photodeposition method.
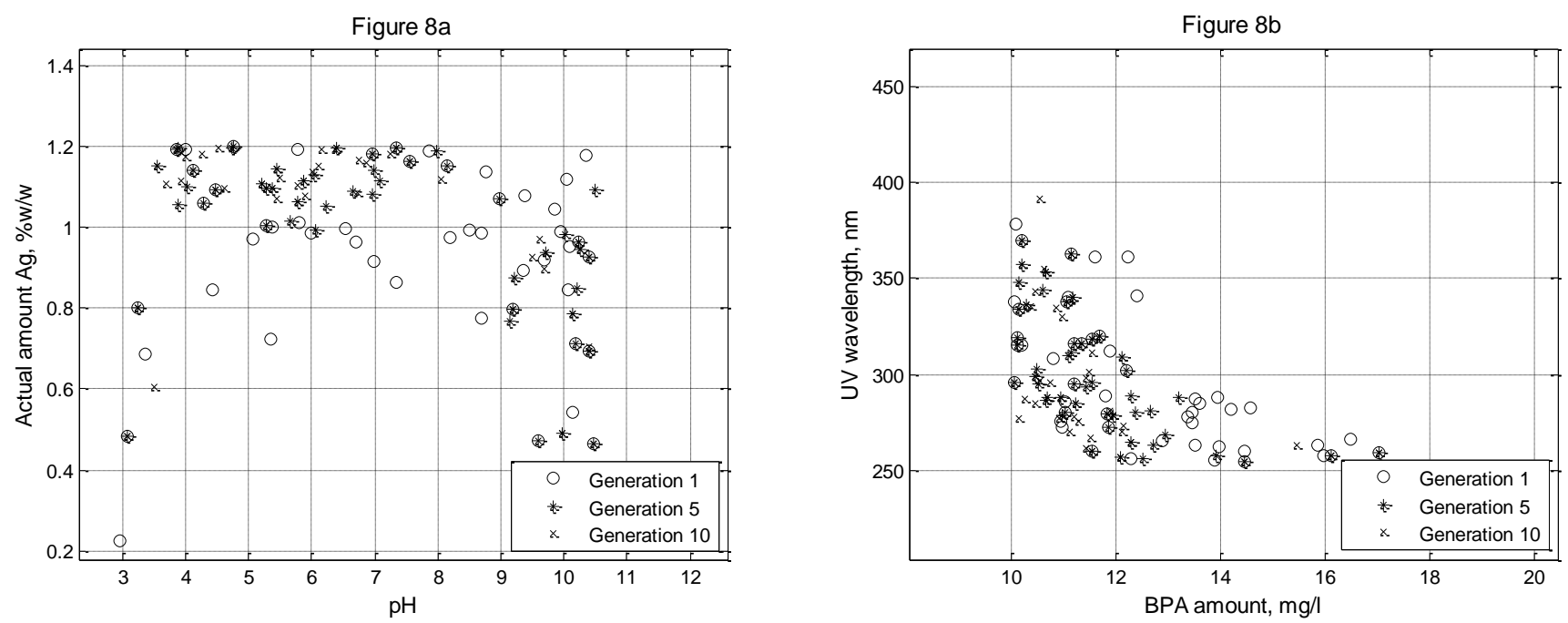

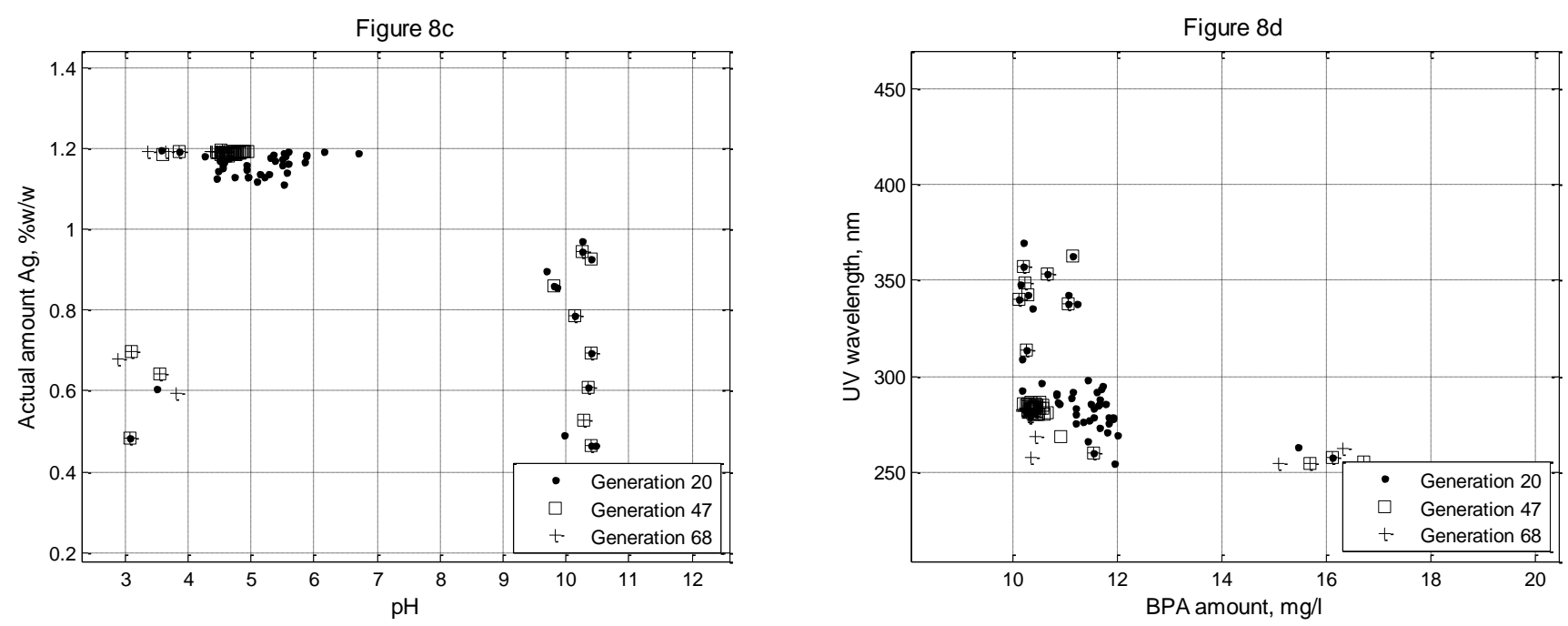

533 Figure 8: Presentation of the 50 optimal conditions in terms of the actual amount of $\mathrm{Ag}$ and $\mathrm{pH}(\mathrm{a}, \mathrm{c}$ ) and the UV 534 wavelength and the BPA amount $(b, d)$, as predicted by the EA optimization on the basis of the ANN ${ }_{2}$-IMP model 535 after 1,5 and 10 generations $(a, b)$ as well as after 20, 47 and 68 generations (c, d).

\subsection{Optimization step 2 - actual amount of silver in the $\mathrm{ZnO}$ photocatalyst}

538 On the basis of the optimal amount of AgNPs defined by the previous optimization step, a second optimization run was carried out in order to define the conditions that would result in

540 the synthesis of a photocatalyst with this optimal amount of silver nanoparticles. So, in this case, the goal was to minimize the objective function defined by the absolute difference between the model response (i.e., the actual $\mathrm{Ag}$ amount) and the desired $\mathrm{Ag}$ amount, as this

543 was defined in the previous optimization step. This second step of the optimization study was

544 based on $\mathrm{ANN}_{1}$ and the results of the EA that was deployed for the solution of this problem are

545 shown in Table 8. In both cases, the error between the desired and attained value was inferior to $0.01 \%$, significantly lower than the associated experimental error of the measurements. 
Table 8: Results of the $2^{\text {nd }}$ optimization step on the synthesis of a photocatalyst with a desired content of AgNPs Optimal photocatalyst synthesis conditions for the photodeposition method (Actual Ag \%w/w = 1.10)

Nominal amount $\mathrm{Ag}, \% \mathrm{w} / \mathrm{w}$

$$
1.00
$$

Time, $\min$

48

Optimal photocatalyst synthesis conditions for the impregnation method (Actual $\mathrm{Ag} \% \mathrm{w} / \mathrm{w}=0.78$ )

$\begin{array}{ccc}\text { Nominal amount } \mathrm{Ag}, \% \mathrm{w} / \mathrm{w} & \mathrm{pH} & \text { Time, } \min \\ 0.69 & 8.5 & 214\end{array}$

552 The respective 2D plots of the evolution of the 50 optimal conditions in terms of the model

553 factors are presented in Figures 9a-9d and 10a-10d, for the photodeposition and the

554 impregnation methods respectively. Note that, as the number of factors is limited to three in

555 this case, both couples that are used in the plots contain $\mathrm{pH}$ as one of the factors.
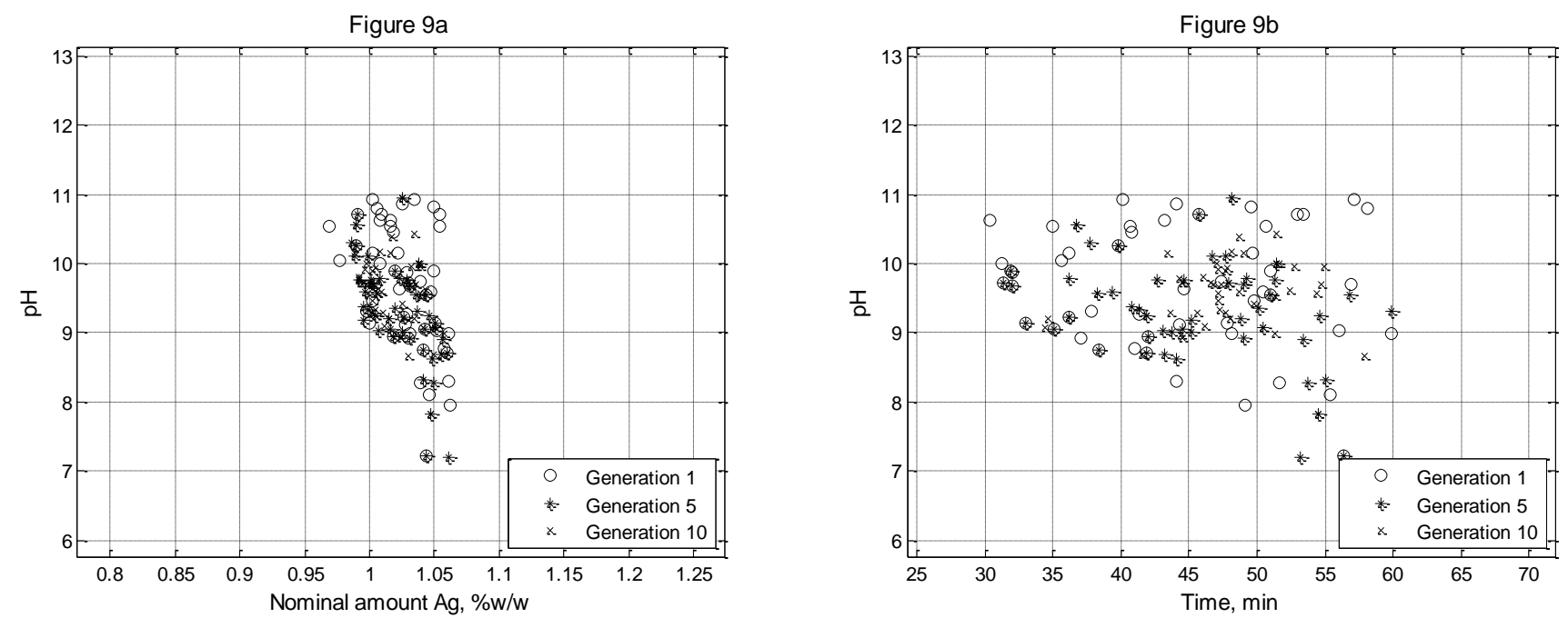

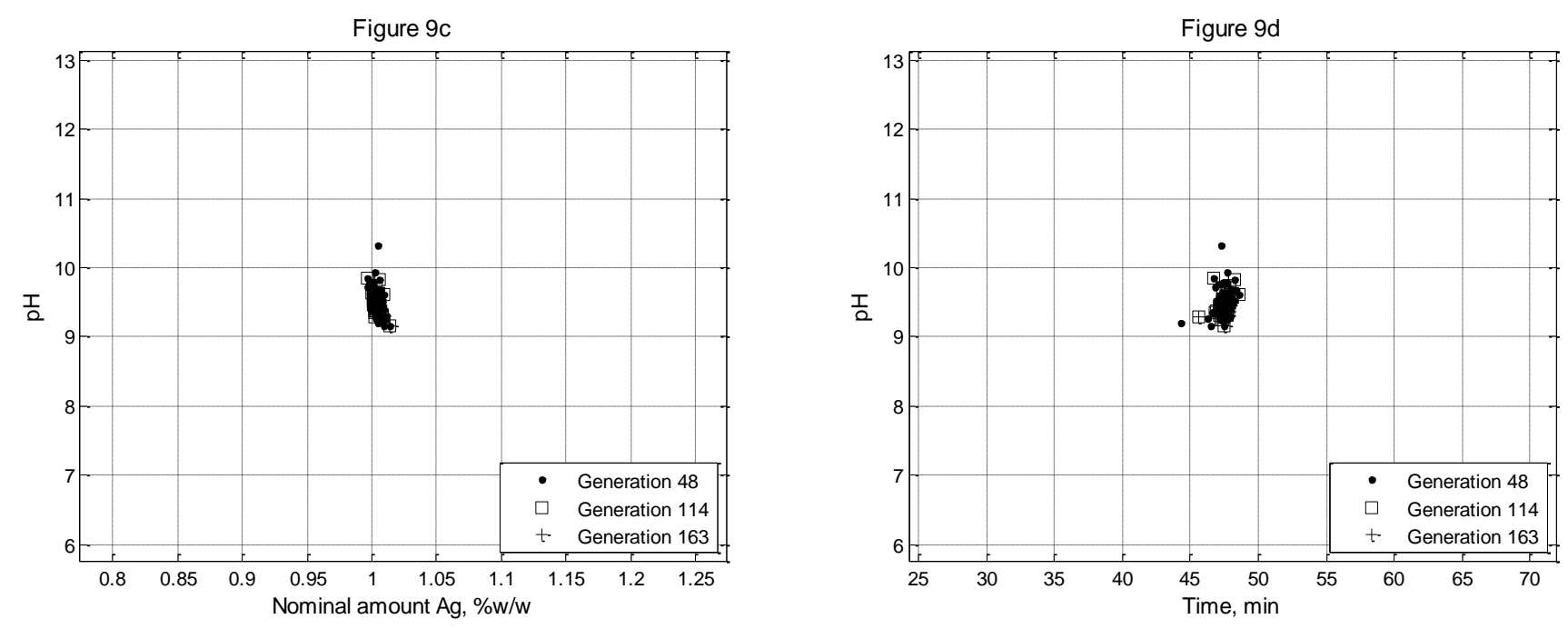

$556 \quad$ Figure 9: Presentation of the 50 optimal conditions in terms of the nominal amount of $\mathrm{Ag}$ and $\mathrm{pH}(\mathrm{a}, \mathrm{c})$ and the 557 reaction time and $\mathrm{pH}(\mathrm{b}, \mathrm{d})$, as predicted by the EA optimization on the basis of the ANN ${ }_{1}$-PD model after 1,5 and 55810 generations ( $a, b)$ as well as after 48, 114 and 163 generations (c, d).

559 The results of these optimization runs are quite similar to the first optimization runs as, once 560 again, the impregnation method seems to provide several alternatives as local minima, 561 especially in terms of the value of the $\mathrm{pH}$, as becomes evident in Figures 10a and 10c. The 562 photodeposition method, on the other hand, has a clear minimum of the objective function that 563 is identified by the EA algorithm already somewhere between the $10^{\text {th }}$ and $48^{\text {th }}$ iteration, 564 despite the fact that the algorithm requires more than 160 iterations to meet the convergence 565 criterion. Finally, a paradox is observed in both optimization results since the optimal nominal 566 amount of $\mathrm{Ag}$ is lower than the desired actual amount of $\mathrm{Ag}$. Once again, this is due to the fact 567 that the models have been trained with experimental data containing such discrepancies, which 568 are caused by the experimental error associated with the experimental protocol and the 569 analytical method (Jasso-Salcedo et al., 2014). This should not be interpreted as an error 570 associated with the modeling framework or the optimization approach. 

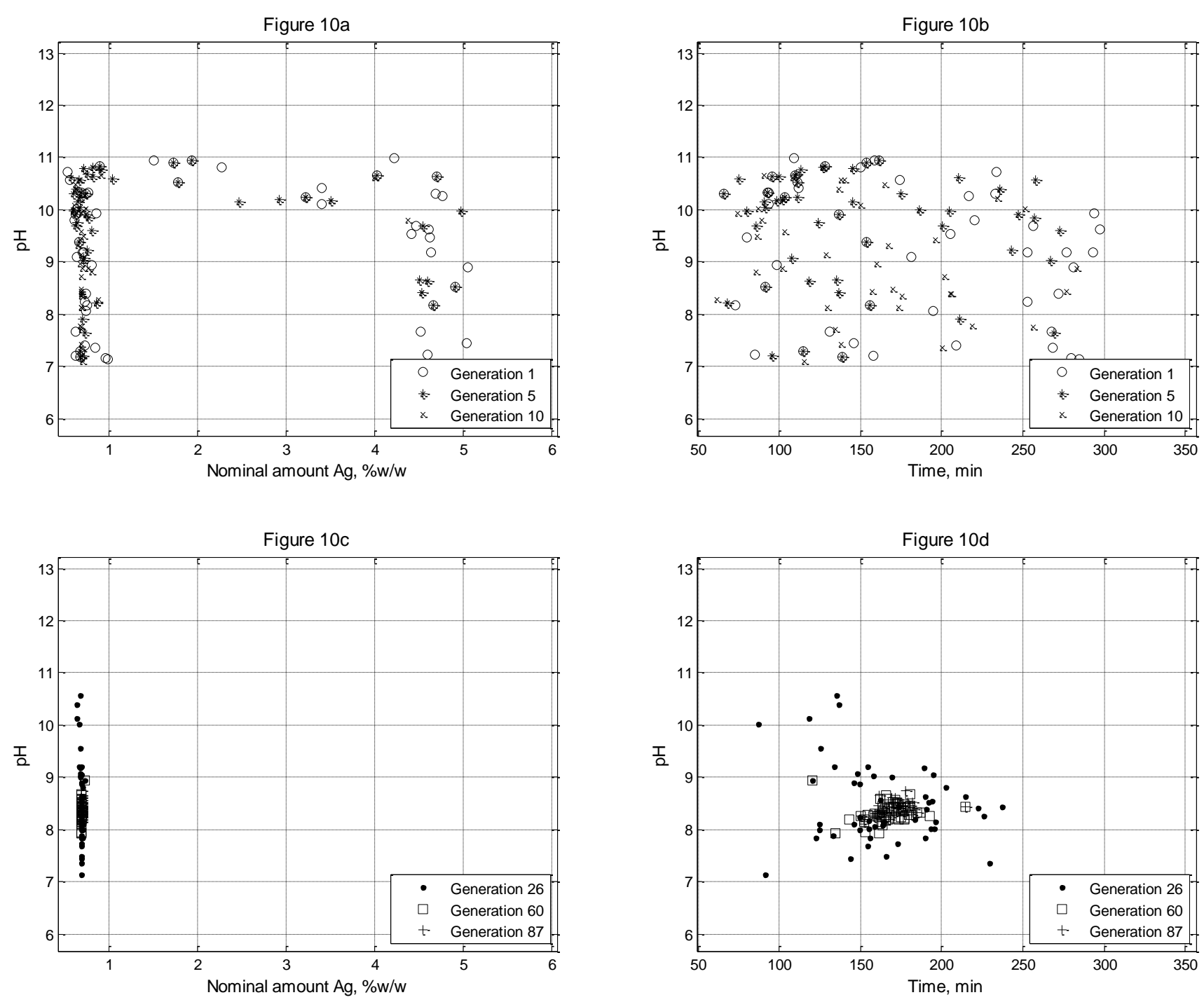

572 Figure 10: Presentation of the 50 optimal conditions in terms of the nominal amount of $\mathrm{Ag}$ and $\mathrm{pH}(\mathrm{a}, \mathrm{c})$ and the

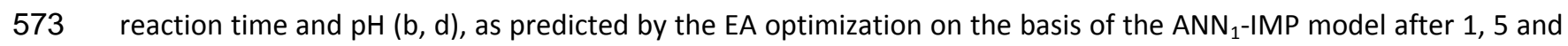
57410 generations (a, b) as well as after 26, 60 and 87 generations (c, d).

\section{Conclusions}

577 In the present work, a modeling framework on the basis of Artificial Neural Networks was

578 presented for the simulation of the effects of two important stages of a photocatalytic process,

579 namely the catalyst synthesis and the photodegradation experiments, on the final 
photodegradation performance of the synthesized photocatalyst. In this respect, a two-stage ANN model was developed, connected by means of introducing the response of the first model as a factor to the second model. The developed models were subsequently introduced in an optimization study, carried out with the aid of an evolutionary algorithm and comprised also of two steps. Through this integrated approach, it has been possible to study simultaneously the 585 effects of a series of important conditions associated with two totally distinct stages of the process and to connect the initial photocatalyst synthesis conditions with its final photodegradation performance.

588 By means of the developed models, the effects of $\mathrm{pH}$, nominal amount of silver nanoparticles 589 introduced in the suspension and reaction time were assessed in terms of their effects on the 590 actual amount of silver nanoparticles that are finally retained on the ZnO surface. At the same 591 time, this amount of attached silver along with the $\mathrm{pH}$, the light wavelength and the initial 592 contaminant amount present in the photodegradation experiments were studied in terms of 593 their effect on the photodegradation performance of the synthesized photocatalyst. This 594 performance was associated with an apparent rate constant, thus eliminating the time from the 595 factors of the photodegradation tests.

596 The decoupling of these two processes that was proposed in this study allowed a better 597 understanding of the nature of the indisputable indirect bond that exists between them. In this 598 respect, it has been shown that an intermediate quality criterion of the photocatalyst, namely 599 the actual amount of silver attached to the ZnO surface that, in turn, can only be controlled by 600 the photocatalyst synthesis conditions, displays a direct effect on its photodegradation 601 performance. Finally, by investigating two different methods of the photocatalyst synthesis, 
602

603

604

605

606

607

608

609

610

611

612

613

614

615

616

617

618

619

620

621

622

623

624

625

626

627

628

629

630

631

632

633

634

635

636

namely a photodeposition and an impregnation method, the study has also demonstrated that

it can display an important effect on the final photodegradation efficiency of the photocatalyst.

Acknowledgements.

This work was supported by CONACYT and the French Ministry of Education and Research

(scholarship PCP/RUI-004-12 granted to AB Jasso-Salcedo).

\section{References}

Amani-Ghadim, A. R., \& Seyed Dorraji, M. S. (2015). Modeling of photocatalyatic process on synthesized $\mathrm{ZnO}$ nanoparticles: Kinetic model development and artificial neural networks. Applied Catalysis B: Environmental, 163, 539-546.

Antonopoulou, M., \& Konstantinou, I. (2013). Optimization and Modeling of the Photocatalytic Degradation of the Insect Repellent DEET in Aqueous TiO2Suspensions. CLEAN - Soil, Air, Water, 41, 593-600.

Antonopoulou, M., Papadopoulos, V., \& Konstantinou, I. (2012). Photocatalytic oxidation of treated municipal wastewaters for the removal of phenolic compounds: optimization and modeling using response surface methodology (RSM) and artificial neural networks (ANNs). Journal of Chemical Technology and Biotechnology, 87, 1385-1395.

Asl, S. K., Sadrnezhaad, S. K., Rad, M. K., \& Üner, D. (2012). Comparative photodecolorization of red dye by anatase, rutile ( $\left.\mathrm{TiO}_{2} 2\right)$, and wurtzite $(\mathrm{ZnO})$ using response surface methodology. Turkish Journal of Chemistry, 36, 121-135.

Babaei, A., Mesdaghiniai, A., Haghighi, N. J., Nabizadeh, R., \& Mahvi, A. (2011). Modeling of nonylphenol degradation by photo-nanocatalytic process via multivariate approach. Journal of Hazardous materials, 185, 1273-1279.

Behnajady, M. A., \& Eskandarloo, H. (2015). Preparation of TiO2 nanoparticles by the sol-gel method under different $\mathrm{pH}$ conditions and modeling of photocatalytic activity by artificial neural network. Research on Chemical Intermediates, 41, 2001-2017.

Bohdziewicz, J., Kudlek, E., \& Dudziak, M. (2016). Influence of the catalyst type (TiO2 and ZnO) on the photocatalytic oxidation of pharmaceuticals in the aquatic environment. Desalination and water treatment, 57, 1552-1563.

Camargo, M., Morel, L., Fonteix, C., Hoppe, S., Hu, G. H., \& Renaud, J. (2011). Development of new concepts for the control of polymerization processes: Multiobjective optimization and decision engineering. II. Application of a Choquet integral to an emulsion copolymerization process. Journal of Applied Polymer Science, 120, 3421-3434.

Cheng, B., \& Titterington, D. M. (1994). Neural Networks: A Review from a Statistical Perspective. Statistical Science, 9, 49-54. 
Clament Sagaya Selvam, N., Judith Vijaya, J., \& John Kennedy, L. (2013). Comparative studies on influence of morphology and La doping on structural, optical, and photocatalytic properties of zinc oxide nanostructures. Journal of Colloid and Interface Science, 407, 215-224.

Das, L., Maity, U., \& Kumar Basu, J. (2014). The photocatalytic degradation of carbamazepine and prediction by artificial neural networks. Process Safety and Environmental Protection, 92, 888-895.

Delnavaz, M. (2015). Application of Artificial Neural Networks for Prediction of Photocatalytic Reactor. Water Environment Research, 87, 113-122.

Dutta, S., Parsons, S. A., Bhattacharjee, C., Bandhyopadhyay, S., \& Datta, S. (2010). Development of an artificial neural network model for adsorption and photocatalysis of reactive dye on TiO2 surface. Expert Systems with Applications, 37, 8634-8638.

Esplugas, S., Bila, D. M., Krause, L. G. T., \& Dezotti, M. (2007). Ozonation and advanced oxidation technologies to remove endocrine disrupting chemicals (EDCs) and pharmaceuticals and personal care products (PPCPs) in water effluents. Journal of Hazardous materials, 149, 631642.

Fernández, R. L., McDonald, J. A., Khan, S. J., \& Le-Clech, P. (2014). Removal of pharmaceuticals and endocrine disrupting chemicals by a submerged membrane photocatalysis reactor (MPR). Separation and Purification Technology, 127, 131-139.

Ferreira, S. L. C., Bruns, R. E., Ferreira, H. S., Matos, G. D., David, J. M., Brandão, G. C., da Silva, E. G. P., Portugal, L. A., dos Reis, P. S., Souza, A. S., \& dos Santos, W. N. L. (2007). Box-Behnken design: An alternative for the optimization of analytical methods. Analytica Chimica Acta, 597, 179-186.

Flint, S., Markle, T., Thompson, S., \& Wallace, E. (2012). Bisphenol A exposure, effects, and policy: A wildlife perspective. Journal of Environmental Management, 104, 19-34.

Fonteix, C., Bicking, F., Perrin, E., \& Marc, I. (1995). Haploid and diploid algorithms, a new approach for global optimization: compared performances. International Journal of Systems Science, 26, 1919-1933.

Frontistis, Z., Daskalaki, V. M., Hapeshi, E., Drosou, C., Fatta-Kassinos, D., Xekoukoulotakis, N. P., \& Mantzavinos, D. (2012). Photocatalytic (UV-A/TiO2) degradation of $17 \alpha$-ethynylestradiol in environmental matrices: Experimental studies and artificial neural network modeling. Journal of Photochemistry and Photobiology A: Chemistry, 240, 33-41.

Georgakis, C. (2013). Design of Dynamic Experiments: A Data-Driven Methodology for the Optimization of Time-Varying Processes. Industrial \& Engineering Chemistry Research, 52, 12369-12382.

Georgekutty, R., Seery, M. K., \& Pillai, S. C. (2008). A Highly Efficient Ag-ZnO Photocatalyst: Synthesis, Properties, and Mechanism. The Journal of Physical Chemistry C, 112, 1356313570.

Ghanbary, F., Modirshahla, N., Khosravi, M., \& Behnajady, M. A. (2012). Synthesis of TiO2 nanoparticles in different thermal conditions and modeling its photocatalytic activity with artificial neural network. Journal of Environmental Sciences, 24, 750-756.

Haykin, S. (1994). Neural Networks: A Comprehensive Foundation (Vol. 2): Macmillan.

Heiligers, B. (1994). E-optimal designs in weighted polynomial regression. The Annals of Statistics, 917-929. 
Jasso-Salcedo, A. B., Meimaroglou, D., Hoppe, S., Pla, F., \& Escobar-Barrios, V. A. (2016). Surface modification and immobilization in poly (acrylic acid) of $\mathrm{Ag} / \mathrm{ZnO}$ for photocatalytic degradation of endocrine-disrupting compounds. Journal of Applied Polymer Science, 133.

Jasso-Salcedo, A. B., Palestino, G., \& Escobar-Barrios, V. A. (2014). Effect of Ag, pH, and time on the preparation of Ag-functionalized zinc oxide nanoagglomerates as photocatalysts. Journal of Catalysis, 318, 170-178.

Khataee, A. R., Fathinia, M., Zarei, M., Izadkhah, B., \& Joo, S. W. (2014). Modeling and optimization of photocatalytic/photoassisted-electro-Fenton like degradation of phenol using a neural network coupled with genetic algorithm. Journal of Industrial and Engineering Chemistry, 20, 1852-1860.

Khataee, A. R., \& Kasiri, M. B. (2010). Artificial neural networks modeling of contaminated water treatment processes by homogeneous and heterogeneous nanocatalysis. Journal of Molecular Catalysis A: Chemical, 331, 86-100.

Kiattisaksiri, P., Khamdahsag, P., Khemthong, P., Pimpha, N., \& Grisdanurak, N. (2015). Photocatalytic degradation of 2, 4-dichlorophenol over Fe-ZnO catalyst under visible light. Korean Journal of Chemical Engineering, 32, 1578-1585.

Kiransan, M., Khataee, A., Karaca, S., \& Sheydaei, M. (2015). Artificial neural network modeling of photocatalytic removal of a disperse dye using synthesized of ZnO nanoparticles on montmorillonite. Spectrochimica Acta Part A: Molecular and Biomolecular Spectrosctroscopy, 140, 465-473.

Kıransan, M., Khataee, A., Karaca, S., \& Sheydaei, M. (2015). Synthesis of Zinc Oxide Nanoparticles on Montmorillonite for Photocatalytic Degradation of Basic Yellow 28: Effect of Parameters and Neural Network Modeling. Current Nanoscience, 11, 343-353.

Klečka, G. M., Staples, C. A., Clark, K. E., van der Hoeven, N., Thomas, D. E., \& Hentges, S. G. (2009). Exposure analysis of bisphenol A in surface water systems in North America and Europe. Environmental Science \& Technology, 43, 6145-6150.

Lee, K. M., \& Hamid, S. B. A. (2015). Simple response surface methodology: Investigation on advance photocatalytic oxidation of 4-chlorophenoxyacetic acid using UV-active ZnO photocatalyst. Materials, 8, 339-354.

Meireles, M. R., Almeida, P. E., \& Simoes, M. G. (2003). A comprehensive review for industrial applicability of artificial neural networks. IEEE transactions on industrial electronics, 50, 585601.

Merabet, S., Assadi, A. A., Bouzaza, A., \& Wolbert, D. (2016). Photocatalytic degradation of indole-4-methylphenol mixture in an aqueous solution: optimization and statistical analysis. Desalination and water treatment, 57, 17039-17050.

Rahman, M. A., Kaneco, S., Suzuki, T., Katsumata, H., \& Ohta, K. (2005). Optimized Conditions for the Solar Photocatalytic Degradation of Bisphenol a in Water Using Zinc Oxide. Annali di Chimica, 95, 715-719.

Rosenfeldt, E. J., \& Linden, K. G. (2004). Degradation of endocrine disrupting chemicals bisphenol A, ethinyl estradiol, and estradiol during UV photolysis and advanced oxidation processes. Environmental Science \& Technology, 38, 5476-5483.

Sabonian, M., \& Behnajady, M. A. (2014). Artificial neural network modeling of $\mathrm{Cr}(\mathrm{VI})$ photocatalytic reduction with TiO2-P25 nanoparticles using the results obtained from response surface methodology optimization. Desalination and water treatment, 1-11. 
Sin, J.-C., Lam, S.-M., Mohamed, A. R., \& Lee, K.-T. (2012). Degrading Endocrine Disrupting Chemicals from Wastewater by $\mathrm{TiO}_{2}$ Photocatalysis: A Review. International Journal of Photoenergy.

Sivanandam, S., Sumathi, S., \& Deepa, S. (2006). Introduction to Neural Networks using MATLAB 6.0: Tata McGraw-Hill Education.

Solomatine, D., See, L. M., \& Abrahart, R. J. (2008). Data-Driven Modelling: Concepts, Approaches and Experiences. In R. J. Abrahart, L. M. See \& D. P. Solomatine (Eds.), Practical Hydroinformatics: Computational Intelligence and Technological Developments in Water Applications (pp. 17-30). Berlin, Heidelberg: Springer Berlin Heidelberg.

Sornalingam, K., McDonagh, A., \& Zhou, J. L. (2016). Photodegradation of estrogenic endocrine disrupting steroidal hormones in aqueous systems: Progress and future challenges. Science of the Total Environment, 550, 209-224.

Tanasa, D. E., Piuleac, C. G., Curteanu, S., \& Popovici, E. (2013). Photodegradation process of Eosin $\mathrm{Y}$ using $\mathrm{ZnO} / \mathrm{SnO} 2$ nanocomposites as photocatalysts: experimental study and neural network modeling. Journal of Materials Science, 48, 8029-8040.

Tijani, J. O., Fatoba, O. O., \& Petrik, L. F. (2013). A review of pharmaceuticals and endocrinedisrupting compounds: sources, effects, removal, and detections. Water, Air, \& Soil Pollution, 224, 1-29.

Vaez, M., Omidkhah, M., Alijani, S., Zarringhalam Moghaddam, A., Sadrameli, M., \& Gholipour Zanjani, N. (2015). Evaluation of photocatalytic activity of immobilized titania nanoparticles by support vector machine and artificial neural network. The Canadian Journal of Chemical Engineering, 93, 1009-1016.

Viennet, R., Fonteix, C., \& Marc, I. (1996). New multicriteria optimization method based on the use of a diploid genetic algorithm: Example of an industrial problem. In European Conference (pp. 120-127): Springer.

Wang, J., Fan, X. M., Tian, K., Zhou, Z. W., \& Wang, Y. (2011). Largely improved photocatalytic properties of $\mathrm{Ag} /$ tetrapod-like $\mathrm{ZnO}$ nanocompounds prepared with different PEG contents. Applied Surface Science, 257, 7763-7770.

Wang, R., Ren, D., Xia, S., Zhang, Y., \& Zhao, J. (2009). Photocatalytic degradation of Bisphenol A (BPA) using immobilized TiO 2 and UV illumination in a horizontal circulating bed photocatalytic reactor (HCBPR). Journal of Hazardous materials, 169, 926-932.

Witek-Krowiak, A., Chojnacka, K., Podstawczyk, D., Dawiec, A., \& Pokomeda, K. (2014). Application of Response Surface Methodology and Artificial Neural Network methods in modelling and optimization of biosorption process. Bioresource Technology, 160, 150-160.

Xi, J., Xue, Y., Xu, Y., \& Shen, Y. (2013). Artificial neural network modeling and optimization of ultrahigh pressure extraction of green tea polyphenols. Food Chemistry, 141, 320-326.

Xie, W., Li, Y., Sun, W., Huang, J., Xie, H., \& Zhao, X. (2010). Surface modification of ZnO with Ag improves its photocatalytic efficiency and photostability. Journal of Photochemistry and Photobiology A: Chemistry, 216, 149-155. 

endocrine disruptor compounds by $\mathrm{Ag} / \mathrm{ZnO}$

771

772 Alma Berenice Jasso-Salcedo ${ }^{\mathrm{a} 1}$, Sandrine Hoppe ${ }^{\mathrm{b}}$, Fernand Pla ${ }^{\mathrm{b}}$, Vladimir Alonso Escobar-Barrios ${ }^{\mathrm{c}}$, 773 Mauricio Camargo ${ }^{d}$, Dimitrios Meimaroglou ${ }^{b}$

${ }^{a}$ Instituto Potosino de Investigación Científica y Tecnológica, División Ciencias Ambientales, Camino a la Presa de 776 San José 2055, Col. Lomas 4a Sección. C.P. 78216, San Luis Potosí, S.L.P., México.

777 b CNRS, Laboratoire Réactions et Génie des Procédés, Université de Lorraine UMR 7274, Nancy, F-54001, France.

778 'Instituto Potosino de Investigación Científica y Tecnológica, División Materiales Avanzados, Camino a la Presa de 779 San José 2055, Col. Lomas 4a Sección. C.P. 78216, San Luis Potosí, S.L.P., México.

780 dUniversité de Lorraine, ERPI, Equipe de Recherche sur les Processus Innovatifs, EA 6737, Nancy, F-54001, France. 781

${ }^{1}$ Present address author AB Jasso-Salcedo: Department of Materials and Environmental Chemistry, Arrhenius

783 Laboratory, Stockholm University, SE-106 91 Stockholm, Sweden. 
Table S1. MSE values corresponding to different network topologies of the developed models

\begin{tabular}{|c|c|c|c|c|c|c|c|c|c|}
\hline \multicolumn{5}{|c|}{$A N N_{1}-P D$} & \multicolumn{5}{|c|}{$A N N_{1}-I M P$} \\
\hline Topology & MSE All & MSE Train & MSE Val & MSE Test & Topology & MSE All & MSE Train & MSE Val & MSE Test \\
\hline $8: 10$ & $5.13 \mathrm{E}-05$ & $7.42 \mathrm{E}-05$ & $1.98 \mathrm{E}-14$ & $1.99 \mathrm{E}-06$ & $10: 10$ & $2.40 \mathrm{E}-03$ & $2.84 \mathrm{E}-03$ & $2.74 \mathrm{E}-03$ & $1.22 \mathrm{E}-04$ \\
\hline $7: 8$ & $5.80 \mathrm{E}-05$ & $8.11 E-05$ & $8.43 \mathrm{E}-06$ & $6.05 \mathrm{E}-06$ & $6: 10$ & $2.41 \mathrm{E}-03$ & $3.27 \mathrm{E}-03$ & $9.80 \mathrm{E}-04$ & $4.02 \mathrm{E}-05$ \\
\hline $9: 8$ & $8.25 \mathrm{E}-05$ & $9.69 \mathrm{E}-05$ & $7.84 \mathrm{E}-05$ & $2.29 \mathrm{E}-05$ & $10: 3$ & $2.42 \mathrm{E}-03$ & $3.46 \mathrm{E}-03$ & 2.17E-04 & $6.83 \mathrm{E}-05$ \\
\hline $5: 4$ & $1.35 \mathrm{E}-04$ & $1.28 \mathrm{E}-04$ & 2.69E-05 & $2.76 \mathrm{E}-04$ & 9:6 & $2.49 \mathrm{E}-03$ & $3.24 \mathrm{E}-03$ & $1.22 \mathrm{E}-03$ & 4.11E-04 \\
\hline $8: 3$ & $1.38 \mathrm{E}-04$ & $1.42 \mathrm{E}-04$ & $1.86 \mathrm{E}-04$ & 7.11E-05 & $9: 2$ & $2.52 \mathrm{E}-03$ & 2.77E-03 & $1.41 \mathrm{E}-04$ & 3.79E-03 \\
\hline $4: 9$ & $1.50 \mathrm{E}-04$ & $7.27 \mathrm{E}-05$ & $6.27 \mathrm{E}-04$ & $1.15 \mathrm{E}-05$ & $7: 5$ & $2.63 \mathrm{E}-03$ & $1.05 \mathrm{E}-05$ & $2.76 \mathrm{E}-05$ & 1.67E-02 \\
\hline $3: 8$ & $1.87 \mathrm{E}-04$ & $2.22 \mathrm{E}-04$ & 5.66E-05 & $1.68 \mathrm{E}-04$ & 3:5 & $2.66 \mathrm{E}-03$ & $3.46 \mathrm{E}-03$ & $8.28 \mathrm{E}-04$ & $9.82 \mathrm{E}-04$ \\
\hline $10: 3$ & $1.93 \mathrm{E}-04$ & $1.71 \mathrm{E}-04$ & 4.13E-04 & 7.12E-05 & $5: 1$ & $2.70 \mathrm{E}-03$ & $3.85 \mathrm{E}-03$ & $2.16 \mathrm{E}-04$ & $1.12 \mathrm{E}-04$ \\
\hline 7:1 & $1.99 \mathrm{E}-04$ & $2.57 \mathrm{E}-04$ & $9.56 \mathrm{E}-05$ & 4.97E-05 & 9:9 & $2.71 \mathrm{E}-03$ & $3.93 \mathrm{E}-03$ & $1.58 \mathrm{E}-06$ & $6.00 \mathrm{E}-05$ \\
\hline $8: 5$ & $2.29 \mathrm{E}-04$ & 5.57E-05 & $3.80 \mathrm{E}-05$ & $1.18 \mathrm{E}-03$ & $6: 2$ & $2.74 \mathrm{E}-03$ & $1.28 \mathrm{E}-03$ & 1.17E-02 & $1.82 \mathrm{E}-04$ \\
\hline \multicolumn{5}{|c|}{$A N N_{2}-P D$} & \multicolumn{5}{|c|}{$A N N_{2}$ - IMP } \\
\hline Topology & MSE All & MSE Train & MSE Val & MSE Test & Topology & MSE All & MSE Train & MSE Val & MSE Test \\
\hline 9:8 & $1.56 \mathrm{E}-04$ & $1.63 \mathrm{E}-04$ & $1.11 \mathrm{E}-04$ & $1.68 \mathrm{E}-04$ & $8: 10$ & 1.10E-04 & 1.69E-04 & 2.79E-11 & $8.81 \mathrm{E}-11$ \\
\hline 17 & 4.39E-04 & $5.34 \mathrm{E}-04$ & 7.90E-06 & $3.64 \mathrm{E}-04$ & 3:10 & $1.39 \mathrm{E}-04$ & $2.15 \mathrm{E}-04$ & $3.14 \mathrm{E}-08$ & 1.10E-08 \\
\hline $8: 8$ & $6.33 \mathrm{E}-04$ & $7.28 \mathrm{E}-04$ & $6.62 \mathrm{E}-04$ & $9.73 \mathrm{E}-05$ & $8: 4$ & $1.50 \mathrm{E}-04$ & $1.23 \mathrm{E}-04$ & 4.01E-04 & $1.48 \mathrm{E}-08$ \\
\hline $4: 9$ & $8.32 \mathrm{E}-04$ & 4.15E-04 & $2.48 \mathrm{E}-03$ & $1.40 \mathrm{E}-03$ & 11 & $2.06 \mathrm{E}-04$ & $1.28 \mathrm{E}-06$ & $2.16 \mathrm{E}-06$ & $1.16 \mathrm{E}-03$ \\
\hline $4: 7$ & $1.04 \mathrm{E}-03$ & $9.44 \mathrm{E}-04$ & $9.74 \mathrm{E}-07$ & $2.59 \mathrm{E}-03$ & $8: 7$ & $5.45 \mathrm{E}-04$ & $7.42 \mathrm{E}-04$ & $6.20 \mathrm{E}-05$ & $3.05 \mathrm{E}-04$ \\
\hline 14 & $1.18 \mathrm{E}-03$ & $1.15 \mathrm{E}-03$ & 7.75E-05 & $2.46 \mathrm{E}-03$ & 9:4 & $8.41 \mathrm{E}-04$ & $6.31 \mathrm{E}-04$ & 3.32E-19 & $2.45 \mathrm{E}-03$ \\
\hline 15 & 1.19E-03 & $1.60 \mathrm{E}-03$ & $2.83 \mathrm{E}-07$ & $1.71 \mathrm{E}-04$ & 9:10 & $1.20 \mathrm{E}-03$ & 5.95E-05 & $2.58 \mathrm{E}-04$ & 6.33E-03 \\
\hline $8: 10$ & $1.22 \mathrm{E}-03$ & $1.37 \mathrm{E}-03$ & $8.44 \mathrm{E}-04$ & $7.48 \mathrm{E}-04$ & $10: 1$ & $1.25 \mathrm{E}-03$ & $1.80 \mathrm{E}-03$ & $2.44 \mathrm{E}-04$ & 2.67E-04 \\
\hline 16 & $1.38 \mathrm{E}-03$ & $1.76 \mathrm{E}-03$ & $6.10 \mathrm{E}-04$ & $9.68 \mathrm{E}-05$ & 5:10 & $1.33 \mathrm{E}-03$ & $2.01 \mathrm{E}-03$ & $1.46 \mathrm{E}-04$ & $3.38 \mathrm{E}-05$ \\
\hline $3: 7$ & $1.48 \mathrm{E}-03$ & 2.01E-03 & $1.22 \mathrm{E}-04$ & 5.52E-05 & 16 & $1.42 \mathrm{E}-03$ & 2.17E-03 & $1.49 \mathrm{E}-05$ & 4.78E-05 \\
\hline
\end{tabular}

